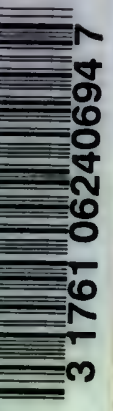

PHYSIOLOGY AND NATIONAL NEEDS 


Digitized by the Internet Archive in 2007 with funding from Microsoft Corporation 
PHYSIOLOGY AND NATIONAL NEEDS 


\section{ANIMAL LIFE AND HUMAN PROGRESS}

EDITED BY

Professon ARTHUR DENDY, D.Sc., F.R.S.

Demy 8vo. 10s. 6d. net.

\section{CONTENTS}

Man's Account with the Lower Animals. By Anthur DENDY, D.Sc., F.R.S., Professor of Zoology in the University of London.

Some Educational and Moral Aspects of Zoology. By Gilbert C. Bourne, M.A., D.Sc., F.R.S., Fellow of Merton College, Oxford, and Linacre Professor of Koology and Comparative Anatomy.

Museums and Research. By C. TATE REgAN, M.A., F.R.S., of the British Museum (Natural History).

Man and the Web of Lifo. By J. Arthur Thomson, M.A., LI.D., Professor of Zoology in the University of Aberdeen.

The Origin of Man. By F. Wood Jones, M.B., D.Sc., Professor of Anatomy in the University of London.

Some Inhabitants of Man and their Migrations. By R. T. Leiper, M.D., D.Sc., Reader in Helminthology in the University of London.

The Future of the Science of Breeding. By R. C. PunNeTt, M.A., F.R.S., Arthur Balfour Professor of Genetics in the University of Cambridge.

Our Food from the Sea. By W. A. Herdman, LL.D., D.Sc., F.R.S., Professor of Zoology in the University of Liverpool.

Tsetse-Flfes and Colonisation. By R. NEWSTEAD, M.Sc., F.R.S., Professor of Entomology in the University of Liverpool. 
MPhy

H

\title{
PHYSIOLOGY
}

\section{AND NATIONAL NEEDS}

\author{
O TED BY \\ W. D. HALLIBURTON \\ M.D., LL.D., F.R.C.P., F.R.S. \\ PROFESSOR OF PHYSIOLOGY, KING'S COLLEGE, LONDON
}

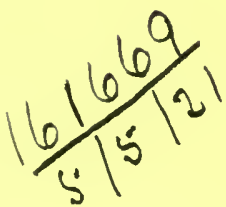

PUBLISHED BY

E.P.DUTTON. $8 \cdot C O M P A N Y$.

681-FIFTH:AVENUE

CD.

NEW.YORK.

ESTABLISHED 1852 



\section{PREFACE}

Thrs little volume is the outcome of a course of public lectures at King's College which I organised this spring under the auspices of the Imperial Studies Committee of the University of London. The neglect of Science in political and similar circles has never been so disastrous for us as in the earlier years of the recent war; our success later on was largely due to the fact that our brave fighting forces were supported at home by the organisation of our scientific resources. Physiology played its part in this great endeavour, and the present book tells some of the story. To include all the many ways in which Physiology is of national importance would have occupied a much larger book: the six articles presented here give samples only, but I trust that those selected will be sufficient to convince the educated public that it is not only in war-time, but in the days of reconstruction and peace that Physiology plays' or should play an important part in our national life.

$$
\text { W. D. HALLIBURTON. }
$$

Kina's College, London,

August 1919. 


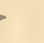




\section{CONTENTS}

Prefact .

Physiology and the Food Problem. By Professol W. D. HaLLiburTon, M.D., F.R.S. . . .

Vitamines, Unknown but Essential Accessory Factors of Diet. By F. Gowland Hopkins, M.D., F.R.S., Professor of Biochemistry in the University of Cambridge

Scurvy : a Disease due to Absence of Vitamine. By Professor A. HARDEN, F.R.S., Head of the Biochemical Department, Lister Institute of Preventive Medicine .

Physiology in the Study of Disease. By D. NoëL Paton, M.D., F.R.S., Regius Professor of Physiology in the University of Glasgow . . . .

The Conservation of our Cereal Reserves. By Arthur Dendy, D.Sc., F.R.S., Professor of Zoology in the University of London

Physicat Training and the Open-air liffe. By M. S. Pembrex, M.A., M.D., Lecturer in Physiology at Guy's Hospital

INDEX 



\title{
PHYSIOLOGY AND THE FOOD PROBLEM

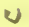 \\ BY
}

\author{
W. D. HALLIBURTON, M.D., F.R.S.
}

PROFESSOR OF PHYSIOLOGY, UNIVERSITY OF LONDON, KING'S COLLEGE 



\section{PHYSIOLOGY AND THE FOOD PROBLEM}

Physiology treats of the uses or functions of the body and of its various parts, so that the relationship of its study to everyday life is more or less obvious, although it is often forgotten.

The science known as Hygiene is the direct practical outcome of physiological knowledge; the health of a nation is its most important asset, and all the means taken to prevent disease come within the scope of Hygiene. It is a curious phase of our national habits that any study of a biological nature is so largely debarred from general education. If a man is to be an engineer, the necessity of a knowledge of engines is obvious. We are all engineers in conducting our life work, yet how few have even a faint idea of the construction or working of the engine called the human body.

In some ancient seats of learning, Physiology still retains its old name, the Institutes of Medicine, and I remember some years ago it was the fashion for physicians to speak of physiology in a somewhat patronising way as the "Handmaid of medicine." One does not often hear this expression nowadays, 
for physiologists have rightfully resented the imputation that their science occupies a humble or menial place. Physicians also have realised that the whole of the science of pathology or disease is the direct outcome of an accurate knowledge of physiology. How many people would place trust in a repairer of unhealthy watches who had no knowledge of the working of a healthy watch ?

During the last four years we have had striking illustrations of the usefulness of the physiologists in the help they have rendered to humanity during the war. It has been a war in which science has played a leading rôle. It has been so for mechanicians of every sort, on the land, on the sea, and in the air. It has been so for the chemists who devised new explosives and new methods of attack, for instance, the poison gases. Many other examples of the chemical side of warfare might be adduced, but let us see what physiologists and physiological chemists have done. They stepped in not to add to the horrors of the battlefield, but to alleviate distress, and the very agent, chlorine, used for destructive purposes became in their hands the basis of the new antiseptics which have done so much to cure the wounds of war.

In former wars the enemy's bullets killed their thousands, but smaller foes, micro-organisms, killed their tens of thousands. How different this present war has been ! Typhoid, the old enemy, has almost 
disappeared, and this is only one of many feats on which preventive medicine, the offspring of physiology, may well be congratulated.

It might be urged that physiology is acting in a presumptuous manner when, as it were, it takes medicine under its wing, and that honour should be given to those to whom honour is due, namely, the medical men in actual practice. All honour certainly to these. Their devotion to duty has made them worthy of the hero's halo. But admitting all that to the uttermost, one cannot overlook the fact that, with some notable exceptions, the clinician is not cut out for research or for grappling with the unknown, either on account of his temperament or because his practical work fills his entire day or because the physiology he learnt years ago has been forgotten and replaced by empiricism. The war has brought to light many new manifestations and varieties of disease, from trench feet up to shell shock, and rapid progress and discovery has been the result of this stimulus to the investigator. Progress during the last four years has probably been more rapid than in the previous forty. In a recent leading article in The Times, a very clear statement on the part physiology has played in this progress occurs. It points out that in nearly every instance it has been this science, an example of Bacon's " more exact inquiry," which has formed the mainstay of the knowledge-seekers. 
What is true of war time must not be allowed to fall into disuse in the period of reconstruction into which we are entering. Let us rather hope that the various committees and enterprises set on foot during the last few years will continue to exist and continue to act with even increased vigour. That frankly means, that in place of spending millions per day on war, the Government must be prepared to spend a few thousands a year in the endowment of research. For the first time in the history of our country, biologists in general and physiologists in particular have been called upon to do national work with more or less official recognition. Hitherto their work has been of national importance, but it has shared the general neglect meted out to scientific endeavour. We have to-day in the present Cabinet a striking sign of grace, for if it contains no physiologists, it has got at the head of two important departments two statesmen who formerly worked at the sister science of anatomy, and so we have the best augury for the future that science is coming into its own.

Among the organisations to which I refer, one must specially mention the Medical Research Committee, which has organised and controlled numerous researches on the new diseases which the war has revealed. A side issue of their work has been the publishing of a medical supplement to the " Review of the Daily Press" issued by the Govern- 


\section{PHYSIOLOGY AND THE FOOD PROBLEM 7}

ment. This review has contained a summary of important foreign news culled from the press of aliens, allies, and neutrals, and its medical supplement has done the same for medical science. A similar publication dealing with animal and plant physiology has been set on foot by the Physiological Society, and is another direct outcome of the war stimulus. One trusts that the Government will continue to support the publication of the medical supplement and extend its usefulness in the time of peace. Such publications are expensive and can never hope to pay their way if they depend on private enterprise alone.

Another important committee, under the presidency of Lord D'Abernon, has dealt with the question of alcohol. The majority of its members were physiologists, and its decisions were the result of scientific research. I remember when I was younger the cant phrase, "You cannot make people sober by Acts of Parliament." This seemed such a conclusive argument that for years and years nothing was attempted in the way of reform. We have seen now what can be done by an act of D.O.R.A., and let us trust that, even if Lord D'Abernon's Committee is no longer an entity, its effects will continue, and that if fresh needs and problems arise the Committee will be reconstituted with enlarged powers. In this connection all will watch with interest that great experiment on the other 
side of the Atlantic in which the use of alcohol is to be entirely prohibited. I might extend my allusions to committees of like nature, but I will mention only one more and it is by no means the least important. I mean the Food (War) Committee of the Royal Society. We hear a good deal now the expression "the silent navy," and an excellent expression it is. One lesson taught us by the recent war, aided by censors of various kinds, is to imitate the navy in holding our tongues. So successfully has the scientific world learnt and practised this lesson that I doubt whether the Royal Society Committee has ever been heard of by the majority of the public. All have heard of the Ministry of Food and have obeyed its edicts, but never knew that all the important decrees of the Ministry were preceded by consultations with the Food Committee of the Royal Society.

Food is a question which appeals to everybody, and although the war is over, and restrictions are being relaxed every day, a good many food problems remain with us, so that the national interest in the question is still keen.

In the early days of food control there was a tendency to pooh-pooh the scientific aspect of the question: these were the days when mistakes occurred, for example, the use of rhubarb leaves. Things did not run smoothly until the Ministry made the remarkable discovery that people who 
have made a lifelong study of a subject are those who really know something about it, and are the only people in the position to give trustworthy advice.

So far has the principle of holding one's tongue been carried that our right hands have hardly known what our left hands have been up to, and I doubt whether even my colleagues know very much more of what my bit of war work has been than that it has had something to do with food. But there is no longer, happily, this need of secrecy, and the immense piles of documents of the Food Committee are now released from the confidential category.

Probably the most important result of scientific interference is that the work has been given an international character, and an Interallied Food Commission, in which the Entente countries participated, met in London, Paris, and Rome. They reached conclusions relating to the distribution and nutritive value of food, the amounts needed under varying conditions of work, etc., and accumulated important statistics on the supplies available, both in the eastern and western hemispheres, which are of the utmost value.

At one of the final meetings at Rome, my friend, Professor Chittenden, the apostle of moderation in food in the United States, and one of the representatives of that country at the Interallied Conference, put it very happily when he said. "In the ancient 
days the edict went forth from Rome that all the world should be taxed; to-day it is from Rome that the world will hear how it is to be fed." But the work of such conferences has not been final: one thing became very clear as time went on, and that is, the imperfection of our present knowledge, and therefore the machinery has been set in action for the future; various topics about which at present we know very little still are to be investigated by international bureaux of inquiry which are to be set up and (one hopes) subsidised.

The daily press has during the last few years made the public familiar with some of the principles of dieting and the way in which the value of foods can be estimated in calories. I do not propose to dwell upon these principles; they can be culled from any elementary primer on physiology. ${ }^{1}$ Moreover it is impossible with the space at my disposal even to allude to such aspects of the food question as the daily amount necessary in various industrial occupations, or to the nutritive value of the many different kinds of food which have been investigated in detail. Instead of this I will select one or two definite examples as illustrations of the sort of work which has been carried out, and of which I happen to have some intimate knowledge. The first of these topics is bread, and as an

1 I have jotted down the main elementary principles of dieting in a brief appendix to this a: icle. 
introduction let me first say a few words on vitamines, a subject on which our knowledge is quite recent.

If an animal is fed on purified proteins, carbohydrates, and fats, with the addition of the necessary salts and water, it soon becomes ill and finally dies, even although the amounts administered are physiologically correct. If the animal is a young one, it ceases to grow under the same conditions. A very small addition of a natural food, such as milk, corrects the evil. Foods as they occur in nature contain something extra, and these extra materials, a small quantity of which is essential for normal maintenance and growth, have been dubbed vitamines, or accessory food factors.

One of them is soluble in water, and is contained in special abundance in the "germ" present in the outer portions of food grains. In certain parts of the world, for example in Japan, polished rice was used as the main article of diet, and the Japanese suffered in consequence from a disease called beri-beri. (dropsy, neuritis, paralysis), not because the rice was poisonous but kecause it lacked the vitamine. If the outer portion of the rice grain is added to the diet the disease is prevented or cured. The Japanese - ure a practical people, and now that the cause of beri-beri is known, the disease is rapidly 'er ing a thing of the past. There are also other tinines; diseases 
due to their absence, such as scurvy, rickets, and probably dental caries, are therefore called "deficiency diseases."

What is true for rice is also true for wheat grains. Our war bread was at first distasteful, and part of the prejudice against it was due to errors in mixing and baking, which can now be avoided. Painstaking researches have shown that the war bread was not only easily digestible by most people

- (including invalids, who submitted themselves to experimentation), it not only enabled an enormous saving to be made in the nation's supply of flour, but, above all, it is of superlative value in containing the health-giving vitamine. ${ }^{1}$

The methods of making such bread and the experimental testing of their digestibility were all organised by the Royal Society Committee, and it was mainly the effect of this Committee's representations which prevented the Government from rationing bread in this country. This was, however, only rendered possible by America's great act of self-sacrifice in depriving herself of wheat in order to supply us and our allies. Here she also acted under scientific advice.

The women of America have loyally. supported the men, and it has been their special duty to look up the old cookery books dating back to times

1 The question of ${ }_{\text {in }}$,ines is considered in full in Professor Hopkins' article, which see (p whis 
when América was not a wheat-growing country in order to discover how other cereals could be adapted to the palate of the American nation.

Just now, however, it is not our daily bread that we worry about so much as our weekly butter.

In the second half of 1917 the shortage in fats became serious and led to a great reduction of the fat ration. The reason was not far to seek, for fats formerly used as food were split in the preparation of glycerine for the manufacture of explosives. A fat chemically is a combination of glycerine with certain organic acids which are called fatty acids, and the question arose whether the fatty acids which remained after the separation of the glycerine could be made available for human consumption.

The question was referred to the Royal Society Committee, and Professor Noël Paton and myself were appointed a small sub-committee to investigate and organise investigations on the matter. It was estimated that some 100,000 tons a year of these fatty acids could have been set free for the purpose if they were found to be suitable for mixing in with margarines. This woul mean a substantial gain to the fat supply of the nation which in pre-war time was estimated at 1,650,000 tons per annum, an amount far above the actual requirement, for fat more than any other food constituent was extensively wasted. One of the duties of our 
little sub-committee consisted in examining and reporting upon various contrivances for fat-saving, but the main issue before us was the possible utilisation of the fatty acids just referred to. We have had assistance from workers in several laboratories and also from important firms, for instance, the Olympia Mills at Selby. After a visit to the Selby Mills, undertaken by my colleague, Dr. Drummond, where he was supplied with the technical details that were necessary, arrangements were made for a supply of fats, mainly. of vegetable origin and of the fatty acids prepared from them, to be sent to the laboratories where experiments were conducted. At that time we did not know how long the war was going to last and so we selected rats as the animals upon which the experiments were made, for a few weeks or months in the life of these animals form a very considerable portion of their life span.

The first specimens received were not appetising, and in fact could not have been rendered fit for human food, but subsequently with improved methods the impurities in the material were lessened so that these were actually employed for experiments upon man. The rats took the fatty acids and thrived upon them and actually produced young during the experimental period, but the ultimate experiment must always be made upon man himself, for it would never do to go to the 
public and say, It is quite safe for you to take this sort of food because rats have done well upon it.

With the help of Professor Leitch of the West of Scotland Agricultural College, the fatty acids were rendered palatable or sufficiently so for three volunteers from the University of Glasgow to take them as their sole fat supply for weeks on end, either spread on bread or mixed with potatoes. At first they concealed the flavour with some jam, but after a day or two they were quite content to take the substitute for butter without any camouflage whatever. This unusual fat-like food produced no ill effects, and was well digested and utilised in the body.

Now that the crisis has passed, the necessity for the use of fatty acids in the manufacture of margarine is not likely to be put into practice, but if the need should ever arise again, we know that they can be used with perfect safety, and it will only remain for the skill of the margarine makers to render them more palatable than in these early enterprises.

A remarkable outcome of experiments of this nature has been to show that, although fatty acids are given with the food, yet the body cells have the power to manufacture glycerine upon the premises so that what enters the nutrient stream is fat, that is the fatty acid is once more combined with glycerine within the body although no glycerine 
has been given in the food. What the glycerine is made from is a chemical puzzle, though, perhaps, those who say that it originates from sugar are not far wrong. We may congratulate ourselves upon British enterprise which has rendered the supply of margarine now so large that coupon restrictions were soon abolished, and modern margarines are in many cases made so attractive and so palatable that the old prejudices against this butter substitute have very nearly disappeared.

In real butter there is present another of those materials called vitamines essential for health and more particularly for the growth of young animals. We do not know its chemical composition but we do know that it is present in this as in most other forms of animal fat; but it is absent from vegetable fats, and as vegetable fats are so largely used ${ }^{1}$ now in margarine manufacture care will have to be taken in the future, by legislative enactment or otherwise, that margarines contain a sufficient admixture of fats of animal origin; there will be danger of "deficiency disease" and stunted growth unless such precautions are taken.

This vitamine though absent from vegetable oils is really of vegetable origin, and during plant growth is found in the green parts. The animal body can make glycerine but is not able to make

1 Previous to use oils are "hardened" by a process known as hydrogenation; this is carried out at high temperatures which would destroy any vitamine if it were originally present. 
vitamine, so that when it appears in the milk of the cow it ultimately came from the grass she ate. This should be remembered in the dietary of the nursing mother, and green vegetables should be insisted upon if she is to make milk efficient for the growth of her offspring. Green vegetables are not suitable as food for young infants, so that if ever in the future there is a danger of shortage of milk it must be the children that get the lion's share of milk and milk products.

Speaking of milk and remembering the establishment of a Ministry of Health, it should be one of the earliest acts of such a ministry to safeguard the health of the State by a pure milk bill: precautions of cleanliness in milking and in the storage of milk should be imperative for milk tradesmen and milk sellers, just as it is in America and Australia. In this way the lives of hundreds of thousands of children who are at present exposed to the diseases conveyed to them in unclean milk may be saved.

Among other matters referred to our subcommittee have been the nutritive value of cocoa butter, and the possibility of lanoline, a substance of which a large surplus stock was on hand, as a constituent of margarine. My readers will be interested to know that the former is of high nutritive value: it is not quite so digestible as 
butter or margarine, but, provided you like or can get to like the flavour, it does no harm; lanoline, on the other hand, although it contains nothing actually poisonous, is entirely useless as a food, being quite indigestible.

I have already mentioned that it has been one of my incidental duties to read a good deal of German medical literature during the past few years, and in that country the food problem has been more acute than it has been with us. One hears, or at any rate heard in the past, a good deal of admiration for German methods, but, so far as one can judge, they do not seem to have mobilised - physiological science in the same way as has been done in this country through the Food Committee of the Royal Society. It would be possible to give many examples of want of scientific advice which the food controllers of Germany suffered from, but one which is typical will suffice. Munich is a town in which the great nutrition school flourished under the leadership of Voit about half a century ago, and if one looks to the food controller's regulations for the feeding of the children of Munich it is enough to have made Voit turn in his grave. The errors were pointed out in the medical journals of that city, and one does not know whether this fell upon deaf ears or not, but even if the scientific advice were taken, a good deal of mischief had already been done and it was 
a case of locking the stable door after the horse was stolen. Lord Rosebery, in a sentence that has stuck in our memories, said some years ago that "we generally muddle through somehow," but in connection with food there has been in this country a minimum of muddle, rationing has gone smoothly, there has been but little hardship, and we are through. How far physiology has been instrumental in helping to bring about this happy result, I may safely leave to the judgment of others.

\section{APPENDIX}

\section{THE MAIN PRINCIPLES OF DIETING}

IN order to explain the word nutrition we may roughly compare the body to a steam-engine. To maintain this in running order, it is necessary (1) to supply it with fuel, and (2) to keep it in repair. The burning of the fuel gives rise to heat and also generates the work which it is the object of the engine to accomplish. Food in relation to the body fulfils the same use, for it undergoes combustion and thus the bodily heat is kept up, and work is rendered possible. Food also achieves the second function, and supplies the material for the repair of the body's framework which undergoes wear and tear as a result of activity. Here, however, the body is superior to the engine; in the case of the latter, repair has to be accomplished by means of "spare parts," or at any rate of materials similar to those originally employed in the construction of the machine; the living body is able to utilise for repair certain materials in the food which are not identical with its own substance, but which are rendered identical in digestive processes. 
This twofold aspect of the usefulness of foods was first grasped many years ago by Liebig, and he divided foods into two groups : (1) the "heat-forming," or more accurately the "energy-forming," foods, which are the fats and the carbohydrates (starch and sugar) ; and (2) the "fleshforming," or better the "tissue-forming," foods, which are par excellence those complex nitrogenous substances termed the proteins or albuminous foods. The proteins, however, in addition are partially burnt in the body, and so serve also as a source of energy. A nutritious diet, then, is one which is able to repair tissue waste and provide the requisite amount of energy.

ENERGY.-When the fuel in the engine's furnace is burnt, there is no real destruction of matter, for the products of combustion (carbonic acid and the like) are equal in weight to the original fuel, plus the oxygen of the air which has entered into combination with it. During this combustion or oxidation, energy is liberated, and energy, like matter, is also indestructible though it exhibits transformations. In the unburnt fuel the energy is latent or potential, but as the coal burns three forms of actual energy or force are liberated : one of these is light, another is heat, and the third is mechanical work which makes the wheels go round. There is a fixed relationship between these forms of energy; heat, for example, can be transformed into mechanical work, but always in a definitely fixed proportion. Consequently energy can be measured by selecting one kind'as the standard, and then the value of other forms of energy can be calculated. The standard which has been selected is the heat unit or calorie.

THE CALORIE is the amount of heat required to raise the temperature of one kilogramme $(2 \mathrm{lb} .3 \mathrm{oz}$.) of water from freezing-point to $1^{\circ} \mathrm{C}$, , and the instruments which measure the calorific value of substances are called calorimeters; these may be briefly alluded to as vessels containing a known weight of water; the material to be 
investigated is burnt inside the calorimeter and the rise of temperature in the water is noted. Every substance has a fixed heat (or energy) value. For example, a gramme (about 15 grains) of starch or sugar when burnt yields 4 calories, and a gramme of fat yields 9 , and this is true whenever or wherever it is burnt. Life is a process of slow combustion, and its activities are the result of the transformation of energy just as in the furnace of the steam-engine. In animal life, save in such exceptional creatures as glow-worms and fireflies, there is no production of light; the chief form of actual energy is heat, and some of this is transformable into mechanical work. Calorimeters adapted to be used for animals and men have shown that the same laws hold there as in the engine; each gramme of fat burnt in the furnace of our body yields 9 , and each gramme of starch or sugar (and we may add here protein) yields 4 calories. The advantage of fat as a fuel is evident, for it yields more than twice as much energy as the same weight of any other foodstuff.

The DaILy CALORIE ReqUiRement will depend on the size of the man and on variations in his activities. A man of average size who stays in bed for the twenty-four hours wants about 1700 in the day to maintain his temperature, to keep his heart beating, his chest breathing, and so forth. A larger man needs more, a smaller man less. The remainder of his calorie supply in an active person can be called upon for the performance of work. It should, therefore, be one of our endeavours in hard times to get rid of superfluous weight. This indeed is the usual effect of reduced diet. The loss of weight is generally beneficial ; it is not progressive after a given time, and one result is a lessening of the figure 1700 (this is called the basal or standard metabolic figure), so then more is available for work performance. - Most people happily do not spend their days in bed, and the old precept that if a man does 
not work neither shall he eat is seldom carried out in practice; but the converse that if he does work he should have more to eat is a sine qua non. The peace-time allowance for a man doing a day's hard muscular labour is food equivalent to about 3500 calories, and under conditions of extreme work this may rise to more than 4000 in a day. Many people in the time of peace and plenty took food of this high calorific value even if they were not hard workers, and it was such people who as a consequence put on weight: it is just these people who lost their extra weight when rationed in war time.

But the man who really is putting forth extra energy must either get it from an increase in his food intake or he has to fall back on his reserves; the first line of reserve is his adipose tissue, and so he becomes thin. This reserve obviously will not last him for an indefinite time, so after a given period, if he still continues to work hard on insufficient food, the more precious protein reserves in his muscles and other tissues will suffer a harmful strain.

A definite example may help us to realise the thing in figures. Take the case of a well-to-do and not over energetic person. His basal metabolic requirement is 1700 calories, and his daily food in peace time gave him 3500 ; that will leave him 1800 calories for muscular work, which probably he did not wholly use, so that he put on a store of fat. Now suppose he is rationed down to 2500 calories per diem; in a few weeks most of his superfluous weight will be lost, and his basal requirement will be lowered also, say to 1500 calories; he will still have 1000 calories left for muscular activities, and this will be all that he can afford to spend without encroaching on his protein reserves.

The Place of Mrat in a Dietary.-Meat is eaten because it forms a concentrated form of easily digestible protein or albumin, and protein is the great repairer of our tissue waste. As a source of energy, it is about equal to carbohydrate and far inferior to fat; considering its 
price its use is therefore not economical. The man who works hard requires no more meat than the man in the arm-chair, and the so-called increased meat ration which was granted during war time to manual workers was in the shape of bacon, that is mainly fat. The "Roast Beef of Old England" is really not the source of more energy, however much the contrary may be believed by those ignorant of physiological principles. An engine called upon to do more work does not necessarily want repair; what it needs is more fuel (coal or petrol). The healthy human engine is on all fours with this, and rationing was directed to deal with healthy bodies; the invalids who did need repair were dealt with on different lines. Meat, however, which was the only form of protein food rationed, is not our only source of protein supply. The flesh of fish, or, for those who can afford it, of game and poultry, is just as valuable as that of sheep and oxen; we can also get proteins in milk, in cheese, in eggs, and also in bread : for bread contains about 10 per cent. There was never, therefore, any fear that we were anywhere near the margin of danger so far as our supply of flesh-forming foods was concerned. Another available form of protein food is that in peas, beans, lentils, and the like. These useful vegetables contain as much protein as beef and mutton, and if properly cooked (aye, there's the rub !) are almost as easily digested. Nevertheless there are proteins and proteins, and some are better adapted to animal nutrition than others; the most adaptable are those of animal origin; but there are some vegetable proteins which are nearly equal to these, and of those the protein of potato stands pre-eminent; the pity of it is that the potato contains so little, but that little is good. The reduction in the supply of butcher's meat was rendered necessary by the diminished supply, but it was quite sufficient for physiological purposes, and the reduction was of great benefit to those who had been big meateaters in the past. 
The Specific Dynamic Action of Protein.-By this one means that protein, and especially meat protein, acts as a stimulant, stimulating the body to a higher heat production; and this increase in heat production is not all utilisable in the execution of mechanical work. Those who have read the works of Arctic or Antarctic explorers must have noted the beneficial action a good meat meal has on the comfort and well-being of the explorers. In a temperate zone like this, except in the winter, this dynamic action of meat is unnecessary, and the distaste for much meaty food, which we all experience in warm weather, is an instinctive recognition of this physiological principle.

Temperance in alcoholic drinks is not the only form of moderation which we all ought to practise; temperance in other stimulants (meat included) is also obligatory.

RATIONS FOR BRAIN-WORKERS.-The brain works economically: any measurable increase in energy-output is negligible, and so it may be at once said that the brainworker requires no increased intake of food. The food must naturally be easily digestible; one cannot expect a man to do good mental work who is suffering from the pangs of dyspepsia, but beyond this anything further is unnecessary. 
VITAMINES, UNKNOWN BUT ESSENTIAL ACCESSORY FACTORS OF DIET

BY

F. GOWLAND HOPKINS, M.D., F.R.S.

PROFESSOR OF BIOCHEMISTRY IN THE UNIVERSITY OF CAMBRIDGE 



\section{VITAMINES, UNKNOWN BUT ESSENTIAL}

\section{ACCESSORY FACTORS OF DIET}

Is many departments of human knowledge the teaching and guidance of science are accepted as final because in these departments the knowledge arose in the first instance from scientific studies and from these alone. Progress in such categories depends entirely upon controlled and recorded observation or upon experiment, and these are the methods of science.

It is otherwise, one might be tempted to say, in regions where mankind can claim abundant and accumulated empirical experience. In connexion with his own nutrition Man's experience has been -needless to say-coterminous with his whole existence. Science may explain that experience, but is unlikely, it might seem, to improve upon experience as a guide. It may supply theory, but where experience has been so great and so continuous it seems unlikely that it could do much to guide practice. This consideration, consciously or subconsciously, accounts, I think, for a widespread feeling that the teachings of science about our food supply are of academic interest only. 
I am to deal, however, with some facts which indicate that, in one direction at least, practice, for lack of knowledge, has for a long time been in danger of going wrong. Experience might doubtless have eventually corrected the error, but it may be hoped that in this case scientific study will forestall experience, which is a much slower and more expensive teacher.

So long as a community can command not only a sufficiency of food but also a variety of foods, and uses these foods in fresh condition, as Nature made them, appetite and instincts (if unperverted) are usually sufficient to secure efficient nutrition for the individual. But when natural foodstuffs are treated artificially; when, for instance, one kind of food material is fractionated, and the consumer presented with a part of it only, or when another material is dried or heated for preservative or other purposes, or, again, when natural foods are sealed up and kept for long periods, it by no means follows that under such conditions the food materials any longer subserve proper nutrition, even though they are eaten in sufficient quantity and satisfy the appetite.

Now questions of diet are proverbially liable to stimulate quackery, and if I were here to discuss the merits of "natural" foods without giving you objective facts I might be suspected of merely supporting certain doctrinaires-self-dubbed " food 
reformers," whose zeal outruns their knowledge. There are facts, however, which support the view that where commercial or other enterprise supplies the public with articles of diet which have been treated or "refined" so as to please the eye, or to accord with a fashion or convenience, it may be encouraging very wrong practice. Related facts show that the public when employing tinned or dried or preserved foods should use them with discretion and supplement them properly.

To the naïve view that the one important factor in nutrition is the quantity eaten the science of the last century added one discriminative aspect, namely, that quality must be considered as well as quantity in so far that the food eaten must in any case contain a certain minimum of protein. It taught that the essential constituents of a diet which promotes proper nutrition are protein, carbohydrate, fat, and mineral salts, the organic materials being always provided in sufficient amount to supply the demands of the body for energy.

What we have lately learnt - though it is remarkable how slowly came a recognition of the factsis that, in addition to the above constituents, which our diets always contain in tangible and easily ascertainable amounts, an efficient diet must also comprise quite other substances, of which the characteristic is that their nutritive importance is out of all proportion to the minute quantity in which 
they are normally consumed. This, I would repeat, is one essential fact in connexion with what we have agreed to call accessory food substances or "vitamines." Their influence on the body is great: their amount as they exist in natural foods is apparently exceedingly small. This is one reason why they have for so long eluded recognition.

Before putting further details before you I will illustrate how great may be the importance to the body of very small amounts of a nutritional factor by reminding you of what still remains the most vivid instance of the phenomena we are concerned with.

In certain rice-eating communities of the East, in Japan, the Malay Peninsula, the Dutch Indies, the Philippines, etc.-where, owing to various circumstances, the diet is more exclusively confined to the single cereal than is the case in the wheateating West, the very serious disease beri-beri is endemic. It is natural for pathologists to look for a positive, rather than what may be called negative, causation in disease, and after the development of modern bacteriology many unsuccessful efforts were made to find a microbic origin for beri-beri. Long before this, it is true, the view had been held that diet played a part in its production and the use of rice was blamed. But the view taken was that the cause was bad rice, rice infected with moulds or other organisms. Only slowly did the under- 
standing arise, and not till quite lately was proof driven home, that the disease only follows when the rice eaten has been so treated as to lose some essential constituent. The natural grain contains a special constituent necessary to the body. Overmilling removes this. Polished rice, unlike whole rice, is a deficient food. Beri-beri is a deficiency disease, due to reliance upon this food.

Though not duly appreciated at first, evidence for this really came with the arrival in the East of modern milling machinery from the West. This brought a very great increase in the number of cases of beri-beri. Now the native methods of treating rice before eating had been such as to leave essentially untouched certain parts of the grain which the steam mill on the other hand completely removes.

The advent of steam milling and the increase of disease were not at once recognised as being correlated; but so far back as 1897 there was brought forward what was irrefutable proof that beri-beri depends not upon infection or staleness in the rice taken as food, but upon the treatment the grain had received in the mill. This proof was due to the Dutch physician Eijkman. The statistics he used dealt with no less than 279,621 individuals, all of them at different times prisoners in the gaols of the Dutch East Indies. The different prisons, owing to their various situations with different and settled 
local customs, were supplied with different kinds of rice, so the conditions for controlled observations were ready to hand.

In 37 prisons unpolished rice was employed: only one of these prisons developed cases of beri-beri. In 13 prisons the rice used was polished rice mixed with unpolished : in six of them beri-beri developed. Out of 51 prisons where the rice eaten was entirely of the polished variety so many as 36 , or over 70 per cent, developed cases of the disease ! If instead of considering the prisons we count individuals, we find from Eijkman's data that for each 10,000 of the prison population there was only one case among those eating unpolished rice, 416 on the mixed rice dietary, and no less than 3900 on polished rice. Confirmatory observations have in later years been made elsewhere, but Eijkman's figures are so conclusive that I need bring forward no others. What, then, is removed by the steam mill of which the importance becomes so evident in its absence? Not the main husk of the grain, for that had nearly always been removed in oriental practice, but just a very thin layer-the "silver skin"-which lies on the outer part of the husk-free seed, together with what we now know to be also important, the germ or embryo. But these structures represent but a very small proportion indeed of the total weight of the grain, and we know, as a matter of fact, that the essential thing or things contained in them 
can amount to but a minute fraction of the material removed. Polished and unpolished rice, as one looks at them side by side, seem to differ so little that it is almost unbelievable that while the latter is an efficient food the exclusive use of the former may lead to fatal results.

But even Eijkman's striking statistics and the facts they brought out did not at once lead to the conception of vitamines. The thought of the pathologist is so accustomed to deal with positive causes of disease - with bacteria - with some intruder, some materies morbi-that he develops a certain habit of mind, and with difficulty believes in causation which has, so to speak, a minus sign.

I will return later to this particular instance of the evil effects of fractionating a natural food material : for the moment, lest you should associate the subject too closely with the idea of actual disease, I will turn your attention into another channel.

As I have already reminded you, the scientific assumption until a few years ago was that the only essential organic constituents of foods are proteins, fats, carbohydrates, and salts. But the scientific data were mostly obtained during the use of natural food-stuffs-meats, cereals, vegetables, etc. These were, of course, known to contain many other substances besides those held to be essential, but because, for the most part, they are present in small amounts, the possibility of their importance was 
always ignored. Clearly the ability of proteins, fats, carbohydrates, and inorganic salts by themselves to support life could only be proved by giving them pure.

Suppose, now, we feed animals with a mixture containing really pure protein, such as purified casein from milk, purified starch, and pure sugar, together with a vegetable fat (I say vegetable fat for a reason which will shortly be made clear), and the requisite mineral salts-what is the result? Not normal nutrition by any means! On such a food young animals fail to grow and all animals, even adults, sooner or later go to ground.

The full significance of these facts will not be appreciated unless it be recognised that these purified diets are perfectly wholesome: they are fully digested, and may be eaten, so far as quantity is concerned, in amount ample for normal growth and maintenance. Something, however - something clearly of the greatest importance-is lacking. Experiments which prove these statements, and the further discriminative experiments to which I shall refer, have hitherto been made almost exclusively upon animals; for the most part, indeed, upon rats, because of the extreme convenience of these subjects. But for those who feel prejudice against applying results so obtained to the nutrition of Man (an unjustifiable prejudice, let me say), I shall later 
offer facts which make a bridge to the case of human nutrition.

The striking thing, the point that we are now concerned with, is the extremely small amount of material which as an addendum will-if rightly chosen-convert these wholly inefficient artificial diets into efficient ones. In some early experiments of my own, for example, the addendum was a minute amount of milk. The amount of solid matter contained in this added milk represented at most three or four per cent of the whole food eaten by the animals, and as most of the constituents supplied in it were already in the diet any special substance must have formed a very small proportion indeed of the whole supply of food. Yet, without this small addendum young animals did not grow : with it they grew satisfactorily. With it they lived; without it they ultimately died. Similar results are got by the addition of equally small amounts of other materials ; but they must be preparations made from plant or animal tissues. They must contain something made originally by living cells. All our natural foods are parts of tissues which have lived. We ultimately owe our supply of them to the plant, and the plant evidently makes and stores certain substances in very small quantity, which are, as experiment proves, as important to the animal and to the human body as the proteins and the starch which it makes in somuch larger quantity. 
Except for those who view nutrition too exclusively from the standpoint of energy supply, there is no reason for surprise in this circumstance.

What should be clearly grasped is the fact that without the minute quantities of accessory substances, perfectly wholesome and, indeed, from the standpoint of their own functions, absolutely necessary foodstuffs are not, in any complete and proper sense, utilised at all. They are absorbed and the energy contained in them is liberated in the body, but the co-ordination of metabolism is absent, and neither material nor energy is employed aright. When the minute addendum is supplied these very same food-stuffs become perfectly available as a whole. We may think of such facts in terms of a very rough analogy. If a house is to be built it is bricks and wood which bulk largely in the necessary supply. The bulk of necessary nails is out of all proportion small, and even that of the mortar is relatively small; but it would be impossible to erect a normal house without at least a minimal supply of nails and mortar. Without them the rest of the building materials would, from the standpoint of a future tenant, be useless. From the facts just dealt with and from those brought to light from the study of beriberi the conception of vitamines emerges. The analogy just used may indeed be wrong. Vitamines may not be concerned with the structure of the tissues, but rather as stimulants 
or catalysts with dynamic functions in the tissues. In any case they are nutritive essentials not directly concerned with the supply of potential energy.

The question will be immediately asked: what, then, is the actual nature of such substances? It must be confessed that we do not yet know. Patient efforts have already been made to effect their isolation, but success has not yet come. But their nature is perfectly objective. We can extract them, precipitate them, redissolve them: but we cannot yet get them completely separated from other substances, and until we can do so we cannot determine their chemical nature. But many facts have been garnered concerning their general character and behaviour, and what in particular we have learned in the last four or five years is to be sure that there is more than one of these substances. There are, indeed, at least three, each one of them having its own function in nutrition.

Consider first-very briefly-the evidence for the existence of two of them. Suppose an animal to be upon artificial diet such as I have already described. Normal growth will fail, as we have seen. But suppose the fat supplied in the artificial mixture to have been butter or almost any other animal fat. Then growth will occur if we merely add to the mixture small quantities of watery extracts made from various plant or animal tissues. A watery extract of the wheat grain, for instance, 
and especially of the cortex or embryo of the wheat ; or, as it is interesting to know, of the "polishings" which are removed when rice is milled. A substance soluble in water, and that in small quantity, is all that is necessary to convert the, by itself, useless diet into a useful one. Suppose, however, that instead of an animal fat, we have supplied in the original mixture a pure vegetable fat. Then the addition of the just-mentioned watery extracts, alone, may be quite ineffective-they fail to make the dietary one which will sustain the animal. Replace, however, the vegetable fat with butter once more, and, given the watery extract, the animal will thrive. Now, the vegetable fat is a perfectly good food. As fat, as serving the special purpose of fat itself in the body, there is no reason to doubt that it is as good as animal fat. But it lacks some constituent which the latter contains, though that something is once more present in very small amounts. It will be seen at once to what this evidence tends. There are at least two vitamines of importance to nutrition, one associated with certain fats and one soluble in water. Both must be present in sufficient amount in any dietary providing proper nutrition. Following American suggestion, we now speak of them respectively as the "Fat-soluble A" and the "Water-soluble B."

The table shows the relative distribution of these two substances in certain natural products, the 
relative quantity of either, when present, being indicated by the number of plus signs:

Fat-soluble. Water-soluble.

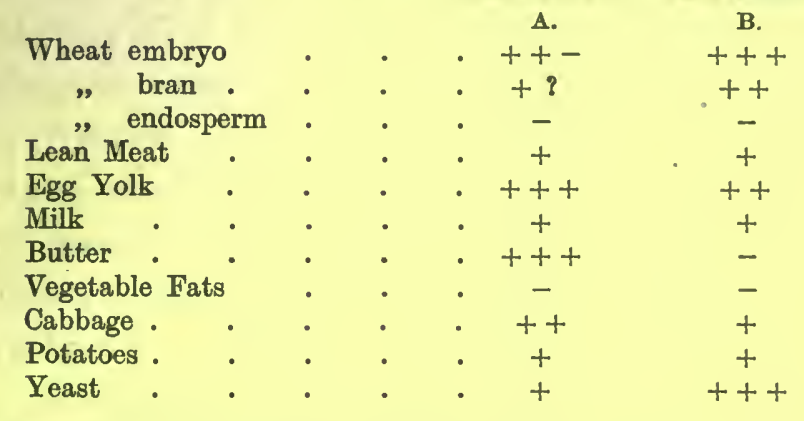

The absence of the fat-soluble vitamine from vegetable fats is not due to its absence from the vegetable structures (seeds, etc.) from which the fats are derived, but to the fact that it is left behind when the fats and oils are expressed or extracted. It is abundant in butter, and is present, as I have said, in most animal fats, but it is, strange to say, absent-or said to be absent-from lard. Now of the water-soluble substance there is one statement which I think can to-day be safely made. It is of special interest because it links these animal experiments with human experience. The watersoluble vitamine proved requisite for growth is the very substance which is necessary for the prevention of beri-beri. It is the substance which rice loses when it is "polished."

I return to beri-beri for a moment. One of the special characteristics of that disease is a dis- 
turbance in the nutrition of the nerves. A form of neuritis occurs, with accompanying paralysis. Now birds, when fed exclusively, upon polished rice, display this particular symptom in a very typical manner, and the fact enables us to perform careful controlled experiments, such as are necessary for determining the distribution of the water-soluble vitamine or, as it may also now be termed, the " antineuritic" substance. After, say, three weeks upon a diet of polished rice a pigeon or a fowl will suddenly develop acute symptoms of paralysis. It is quite easy to cure or prevent these symptoms by adding other food-stuffs to the rice, and if known amounts of them are added it is possible to estimate approximately the relative richness of various foods in this water-soluble or anti-neuritic factor.

So much for the water-soluble vitamine. Is now deprivation of the factor associated with fats also followed by symptoms of actual disease? The experimental study of its effects is more difficult than in the case of the other factor. Deprivation of the latter is almostimmediately felt; but in their own fat stores animals possess a supply of the fatsoluble vitamine, and when it is absent from their diet they seem able to mobilise this supply for the purposes of their active tissues. Not till this internal store is exhausted, or reduced to some minimal value, is its absence from the diet fully felt. Clearly, different individuals will, either from differences in 
their previous nutrition, or from idiosyncrasy, vary in respect of their store of fat and its associated vitamine. It is more difficult, therefore, in the case of the fat-soluble factor to obtain completely consistent results during experimental feeding. Nevertheless all animals ultimately fail when this factor is missing from their food.

The probability is growing that there is one disease-and it is a disease of serious import to the community-in which a dietetic error related to a deficiency in the fat-soluble vitamine plays a causative part. I allude to rickets. We have in this connexion, it is true, not yet the concordant evidence from various sources which exists in proof of the origin of beriberi or of the general importance of vitamines. The case depends at the moment mainly upon the remarkable experimental results obtained by my friend and former pupil Dr. Edward Mellanby: but his work is by no means without the support of other evidence. It is easy, he has found, to construct a diet upon which dogs, though kept in healthy surroundings and given exercise, speedily develop the characteristic symptoms of rickets. It is easy to prevent this by suitable additions to the dietary, in particular by giving certain fats. The fats which are specially efficacious are those which, from other evidence, we know to be rich in the fat-soluble vitamine. Vegetable fats, free from the vitamine, are without effect. The con- 
clusion seems to be inevitable that in some wayon lines perhaps not yet fully cleared up-rickets arises when fat-soluble vitamine is deficient in the food. Other factors, such as a generally deficient hygiene, may be contributory, but I for one am quite convinced that the dietetic error is the primary cause. No whit less important is the fact demonstrated by Mrs. Edward Mellanby that deficient diets such as those which induce rickets, also involve grave errors in the growth of teeth in young animals. We have had little suspicion until lately that the quality of the fat supply in the diet could have an éffect such as this.

As a fat rich in the vitamine and capable of preventing rickets in dogs, cod-liver oil stands preeminent. It has been long known that the oil favourably influences the course of rickets in infants, a fact discovered empirically and without knowledge of vitamines; but a successful therapeutic measure is much more likely to gain general credence and to establish itself in practice if a rational basis for it is made clear. Moreover, the recent attention given to the importance of qualitative factors in food has led to the use of cod-liver oil in the prevention of rickets with successful results. These bring observations upon human infants directly into line with Dr. Mellanby's experiments. The following are striking figures relating to infants in a negro community of the United States. In this community 
the dietetic standards are low and unsatisfactory, and its children are greatly prone to rickets.

The following table shows the extraordinary prophylactic results of administering cod-liver oil.

\begin{tabular}{|c|c|c|c|c|}
$\begin{array}{c}\text { Total oil } \\
\text { administered. }\end{array}$ & $\begin{array}{c}\text { Duration of } \\
\text { Treatment. }\end{array}$ & $\begin{array}{c}\text { No. of } \\
\text { Infants. }\end{array}$ & $\begin{array}{c}\text { Infants } \\
\text { developing } \\
\text { Rickets. }\end{array}$ & $\begin{array}{c}\text { Percentage of } \\
\text { Non-rachitic. }\end{array}$ \\
\cline { 1 - 2 } 54 oz. & 6 Months & 32 & 2 & $93 \%$ \\
$23 \mathrm{oz}$. & 6 Months & 5 & 1 & $80 \%$ \\
$21 \mathrm{oz}$. & 4 Months & 12 & 5 & $58 \%$ \\
None & $\ldots$ & 16 & 15 & $6 \%$ \\
\hline
\end{tabular}

In the case of the disease scurvy, which arises when no fresh foods are available, the cause is again deficiency in a subtle but indispensable element for nutrition. So important is the subject of scurvy, and from the standpoint of dietetics so suggestive, that you are to hear from Professor Harden a special lecture devoted to it. It is necessary, however, that I should mention it because we learn from this disease that at least one other vitamine exists, quite distinct from the two hitherto considered. The antiscorbutic factor, unlike the antineuritic or the fat-soluble substance, is very unstable. These last show considerable resistance to heat and do not necessarily disappear when food-stuffs are kept, even for long periods, whereas the antiscorbutic substance is rapidly destroyed when fresh food-stuffs are heated, dried even at low temperatures, or kept too long.

Another disease which may be mentioned is one 
to which maize-eating communities are prone. I allude to pellagra. I do not propose to discuss it, but to show how wide a ground the subject of this lecture may ultimately be found to cover. I would point out that the many theories as to the origin of pellagra which have previously held the ground seem, at the moment, to be giving way under the pressure of facts and to be yielding to the view that pellagra too is due to the absence of some specific necessary nutritional factor from the diet.

It would be grave error to deny that such facts and considerations as have been now discussed are of practical and even of national importance. Our troops abroad during this war have suffered from scurvy, as they have done in previous wars. Wherever bodies of men-soldiers, sailors, or explorersare long removed from the sources of fresh foods scurvy is wellnigh inevitable. But the severe sufferings which were undergone during the siege of Kut, for instance, might never have occurred if the authorities responsible for the equipment of the expedition had had real belief, such as grows from scientific study, in the importance of antiscorbutics rather than the half-faith which is common, especially had they possessed the quantitative information available as to the distribution of the antiscorbutic factor in different materials.

At home the variety in our foods may be sufficient to secure that actual deficiency disease shall, so far 
as adults are concerned, remain absent. If the necessary accessory factors are missing from one article of diet they will probably be supplied in others. It is by no means so sure that this remains true in the case of the child population. I would ask you here to give your attention to certain matters of fact, hoping that you will not think them trivial because they concern food-stuffs that are so familiar.

First, consider our bread supply. The ancient controversy concerning the relative merits of brown and white bread has been tainted by prejudice. We have had enthusiasm without knowledge on the one side-often mere quackery - and to some extent at least we have had the influence of trade interests on the other side. I hold no brief for whole-meal bread. I think the well-fed and well-to-do public may be justified, now the war is over, in insisting upon returning to its very white loaf, if this loaf suits its taste and appetite better than any other: Other articles eaten will surely supply any deficiency. It is well to face the facts, however. The elaborate milling, the "refining" which the wheat grain suffers before it appears in the form of our white flours, deprives it entirely of its water-soluble vitamine. If our pure white wheaten flour were in this country to form so large a proportion of the whole diet as rice does in the East, beriberi would with certainty appear among us. Indeed, in certain 
limited communities it is said to have followed the use of white bread. The wheat grain, no less than the rice grain, shows that an essential nutritive factor may have an unequal and limited distribution in a natural product, and illustrates the danger of "fractionating" natural foods to which I referred in my opening remarks.

It is clear that the danger of any deficiency in bread becomes the greater the more it bulks as a constituent of the whole diet. In the case of the poor-and especially the children of the poor-it undoubtedly bulks largely. Consider, again, the question of margarine as a substitute for butter. If the margarine is made wholly of vegetable fats it lacks the fat-soluble vitamine. It is not by any means so trivial a point as it may seem to remember that brown bread and butter is, from the standpoint of vitamine supply, an excellent combination, while white bread and margarine may be a desperately bad one.

[Speaking in parenthesis, I happen to be aware from personal knowledge that the margarine industry in this country is quite alive to the significance of the facts. Given full liberty of action the trade is, I believe, both willing and able to turn out products lacking the reproach of this deficiency.]

We must remember, again, that polished rice contributes not a little to the table of the poor, especially in some districts, and is often eaten plain 
boiled. Many of the advertised proprietary breakfast foods and invalid foods are practically vitamine free.

In connection with the antiscorbutic vitamine in particular let it be called to mind that tinned foods are largely used in poor households, for one thing because they often need no cooking. In these very households salads are rare, and during those periods of the year when fruit is dear extraordinarily small amounts of fresh food-stuffs are consumed at all.

Yet, it may be said, in spite of all this, beriberi or pellagra or any disease like them is unknown in this country ; and scurvy is, to say the least of it, very rare. But disturbances in health may exist without arriving at the extreme stage when the appearance of a severe set of symptoms leads to the recognition of actual disease. In particular is this true of conditions of malnutrition, and, unless the considerations I have put before you are wholly baseless, malnutrition may arise irrespective of the quantity of food eaten. It may depend not upon insufficient food but upon badly-treated foods or upon an ill-chosen combination of foods. There is no point in all that I have said that I would like to emphasise more than this. Absence of an essential vitamine from the food means disease: but no more than a relative deficiency of a vitamine may mean bad nutrition. In my own opinion at least the diets of the poor-and once again it is the 
children who are chiefly concerned-often display such deficiency. In connection with a point such as this a study of national supply or even of family budgets gives only partial information. Even when the total family food-budget is satisfactory, ignorant and ill-judged feeding of the child members is both possible and common.

The worst of it is that at present the facts are not generally recognised even by the medical profession, and the ill-health with which such deficiencies as we have been considering are associated is, in my belief, misunderstood and wrongly treated.

The case of rickets, however, stands out. Rickets is very common in this country. True rickets is a disease which, though crippling, is not fatal in itself. It is, nevertheless, a factor of supreme importance to the country. because of its indirect effect upon the infantile death-rate. The child who is rickety is much more prone to other ailments -much more vulnerable in all respects-than a normal child. I will not dogmatise with regard to its origin. The mere suspicion that it may be due to a specific dietetic error, such as a deficiency in the supply of the fat-soluble vitamine, should awaken instant interest. Once we are convinced of the primary importance of this factor it will become of national importance to look to the question not of the quantity alone, but of the quality of the fats in the diets of infants and of nursing mothers. 
Mention of the nursing mother brings me to the last point with which I propose to trouble you. Evidence has accumulated to suggest that vitamines are not made in the animal body. The animal depends ultimately upon the plant for a supply. They accumulate in the tissues of herbivorous animals, and there, as well as in the plant, they are available for human consumption. But if vitamines are not made in the body at all, this means, in the case of the nursing mother, that if she consume a diet deficient in vitamines her milk may ultimately become deficient-to the complete detriment of the nutrition of her child. Animal experiments have already revealed such deficiencies in milk. It will be seen that the whole question of infant feeding is one in which a knowledge of these special accessory food factors is particularly important. The deficiencies which we have been considering are indeed of more urgent importance in connection with the nutrition of the young than when adults are concerned. Hence what I believe to be the national importance of the subject. Whether this importance prove ultimately to be less than some of us believe, or whether-for this is quite possible - it may prove to be of as yet unsuspected importance, it should in any case awaken public interest. We are yet at the bare beginning of its study. 



\title{
SCURVY: A DISEASE DUE TO ABSENCE OF VITAMINE
}

BY

\author{
Prof. A. HARDEN, F.R.S.
}

HEAD OF THE BIOCHEMICAL DEPARTMENT, LISTER INSTITUTE OF PREVENTIVE MEDICINE 



\section{SCURVY: A DISEASE DUE TO ABSENCE OF VITAMINE}

IT is unnecessary under the circumstances of the present lecture for more than a brief mention to be made of the fact that modern research in dietetics has established the existence of no less than three indispensable accessory substances, the presence of which in the diet is essential for the complete development of the higher animals, and the absence of which leads to cessation of growth, disease and death. Although, however, the ideas of accessory food factors or vitamines and of deficiency diseases due to the absence of these from the diet are essentially modern, and have indeed been developed within the last decade, scurvy, one of the best defined deficiency diseases, was long ago recognised as being due to a defective diet. Among a seagoing people like the English, scurvy-the scurvy, as it was always termed-was but too familiar, and a glance through the history of the extensive explorations of the sixteenth and seventeenth centuries teaches us what a dread and terrible scourge scurvy was at that time. 
The remedy-fresh meat and vegetables-was well known, but no means existed in those days for providing ships with these desirable commodities on their slow and protracted voyages. It seems to have been quite a common misfortune in the seventeenth century on the long voyage to India to be compelled to leave a large proportion of the crew at the Cape-stricken with the scurvy. Lind, the historian of scurvy, in his quaint and racy Treatise on the Scurvy (2nd ed., London, 1757) speaks in no uncertain tone both of the cause of the disease and of the most rapid and convenient remedies, correctly ascribing it to abstinence from fresh vegetable food. Scurvy seems also to have been common among the civilian population, owing no doubt to the scanty allowance of meat and green food available for the poorer classes. Thanks to the increased rapidity of transport and the improved facilities for the provision of fresh meat, vegetables and fruit, adult scurvy has become much less familiar in our days and occurs comparatively rarely except in cases of long-continued absence from centres of civilisation, such as arise in polar expeditions or under the strenuous conditions of modern war.

Less rare, perhaps, though fortunately far from common, is infantile scurvy, first clearly differentiated from rickets by Cheadle and by Barlow in the 'seventies and 'eighties of last century, and now 
fully recognised as due to the same causes and subject to the same remedies as adult-scurvy. Although few infants develop scurvy in its severe form there is evidence that incipient scurvy, arising from imperfect diets and causing general malaise, is much more frequent.

In spite of the rarity of scurvy in normal times, comparatively slight modifications in the usual conditions of food supply rapidly lead, even in this country, to the development of the disease, especially among those accustomed to a one-sided diet. Thus, failure of the potato crop in Ireland in $\mathbf{1 8 4 7}$ was followed by an outburst of scurvy, as was also the case in Norway in 1904, and the recent shortage in the spring of 1917 was marked by outbreaks of scurvy in Glasgow, Manchester and Newcastle. Similar occurrences are recorded by Hess in America, ${ }^{1}$ where a shortage of potatoes in the spring of 1916 was followed by the occurrence of no less than 200 cases in a single institution.

Such facts mean, as pointed out by Hess, that a considerable number of the population are never very far removed from the safety line in this respect, if they are not actually suffering from a partial deficiency.

In time of war scurvy rapidly appears, and numerous instances of this have occurred during the past four years-as, for example, at Kut 1 J. Amer. Med. Assoc., 1918, 71, 941. 
during the siege. In the American civil war no less than 30,714 cases of scurvy occurred among white troops, and 383 deaths were attributed directly to that disease.

Artificially fed children are, as we shall see, even nearer to the scurvy line; and scurvy, incipient or declared, must be regarded as an ever-present danger, especially in the first year of life.

\section{EXPERIMENTAL SCURVy}

As happens frequently if not invariably in the study of disease, little progress was made in our exact knowledge of the conditions giving rise to scurvy, whether in the adult or the infant, and of the best remedies, until it became possible to investigate the question in the laboratory by experiments on animals. This important advance was made in 1907 by the Norwegian investigator Axel Holst, ${ }^{1}$ who found that guinea-pigs developed a disease closely resembling human scurvy when fed on a diet of grain and water. By supplementing this diet with various materials the antiscorbutic value of the latter can be gauged; and further research carried on during recent years in this country at the Lister Institute under the direction of Dr. Harriette Chick has developed this procedure into a quantitative method of some degree

1 J. Hygiene, 1907, 7, 619 ; Holst and Frölich, Zeitsch. Hygiene, $1912,72,1$. 
of accuracy. By this means not only can the general distribution of the antiscorbutic principle be ascertained but the relative values of different food-stuffs can be determined and the effect - of various physical and chemical agents on their antiscorbutic potency can be studied.

A more perfect diet for the guinea-pig is obtained by substituting autoclaved milk for water, as the weight of the animal is then better maintained. On such a diet guinea-pigs develop the symptoms of scurvy and commence to lose weight in 14-21 days, and die in about 25-30 days. At the postmortem a pathological picture very similar to that of human scurvy is disclosed. Subcutaneous intramuscular haemorrhages, the latter specially pronounced in the thigh region, are well in evidence. Subperiosteal haemorrhages are also to be observed. The costochondral junctions are abnormally enlarged and haemorrhaged. The bones are very brittle and the teeth are loose. Young growing guinea-pigs are used, but on the experimental diet practically no growth occurs. The weight of the animal is maintained at an almost constant level for 14-21 days and then rapidly falls off.

Distribution of the Antiscorbutic Accessory Factor. -Accurate information as to the distribution of the antiscorbutic principle and as to the effect of various physical and chemical agents upon it can only be obtained by working on a quantitative 
basis. Thus in order to ascertain the relative value of different antiscorbutics it is necessary to establish in each case the minimum amount of the material which wards off scurvy, and each experiment of this sort must be carried out on several animals in order to eliminate the effect of individual idiosyncrasies.

The general results of the experiments so far made is shown in the following tables, in the first of which the distribution of the principle in a number of food materials is indicated, and is contrasted with that of the antineuritic and fat-soluble accessories, the relative abundance being indicated by the number of + signs. In the second a roughly quantitative estimate is made of the relative amounts present, taking that in fresh cabbage leaves-one of the richest sources which we have -as 100.1

\section{TABLE I}

SHOWING THE DISTRIBUTION OF THE THREE ACCESSORY FACTORS IN SOME OOMMON FOOD-STUEFS

\begin{tabular}{|c|c|c|c|}
\hline & Antiscorbu & $\begin{array}{l}\text { Antineuritic or } \\
\text { Water-Soluble B. }\end{array}$ & Fat-Soluble \\
\hline Butter, . & . $\quad 0$ & 0 & $++t$ \\
\hline Vegetable Fats, & 0 & 0 & 0 \\
\hline Lean Meat, & + & + & + \\
\hline Cow's Milk, . . & . $\quad+$ & + & ++ \\
\hline ,, Dried, . & - Small & + & ++ \\
\hline Eggs, . . . & - $\quad 0$ & +++ & ++ \\
\hline Cereals, Wholo grain, & & + & + \\
\hline $\begin{array}{l}\text { Germ, } \\
\text { Peas and Lentils, Dried }\end{array}$ & $\begin{array}{l}0 \\
0\end{array}$ & $\begin{array}{c}+++ \\
++\end{array}$ & $\begin{array}{c}++ \\
+\end{array}$ \\
\hline
\end{tabular}

1 For permission to include some of these numbers, which have not yct been published, I have to thank Miss Chick and her colleagues. 


\section{TABLE I.-Continued}

Antiscorbutic. $\begin{gathered}\text { Antineuritic or } \\ \text { Water-Soluble B. }\end{gathered}$ Fat-Soluble A.

Germinated Cereals

and Peas, etc., . ++

Cabbage, . +++

Potato, Boiled, . . +

, Raw,

Lemon Juice, . $\quad+\quad++$

Yeast Extract, . 0

Meat Extract, . 0

Beer, . . . 0

$$
\begin{array}{cc}
++ & + \\
+ & ++ \\
& \\
\text { probably none } & \text { probably none } \\
+++ & \text { probably none } \\
0 & 0
\end{array}
$$

\section{TABLE II}

SHOWING THE RELATIVE AMOUNTS OF ANTISCORBUTIO FACTOR IN SOME COMMON FOOD-STUFFS

VEGETABLES

FRUITS

Fresh Cabbage, . $\quad$ - 100 Lemon Juice, - . 66

Swede Juice, - . 40 Orange Juice, - . 33

Germinated Lentils, . 20 Lime Juice, . . 10-15

Cooked Cabbage, . . 20 Grapes, . . less than 5

Runner Beans, . . 20 Meat Juice, . . less than 5

Boiled Potato, . $\quad 5$ Cow's Milk . . . 1

Dried Vegetables, . $\quad 1 \cdot 6$

It will be seen that the chief sources of the principle are green vegetables, tubers, roots and fruits, whereas seeds are totally devoid of it, and animal products such as meat and milk contain relatively very little. An interesting and important observation was made by Furst, ${ }^{1}$ and has been confirmed by Chick and Hume, to the effect that the antiscorbutic principle is produced during the germination of seeds. In cases of necessity, therefore, dried peas and lentils-themselves devoid of antiscorbutic properties-can be converted into

1 Zeitsch. Hygiene, 1912, 12, 121. 
powerful antiscorbutics by the simple process of steeping and germination. This has been suggested as a valuable means of protection against scurvy, and the value of germinated beans as a cure for scurvy has been demonstrated by Wiltshire, ${ }^{2}$ who treated a number of military patients with this material and found it quite as efficacious as an equal weight of lemon juice.

Properties of the Antiscorbutic Accessory. Effects of Heating and Drying.-The outstanding property of the antiscorbutic accessory factor is its instability. When the materials containing it are heated, dried, or even simply preserved, their antiscorbutic properties gradually disappear. The effects of heating and drying are of special practical importance, and have been investigated in this country by Delf and Skelton, ${ }^{3}$ and in America by Givens and his colleagues. ${ }^{4}$ When cabbage is dried at a low temperature and subsequently stored for two to three weeks at laboratory temperature, it loses more than 93 per cent of its antiscorbutic potency, and a further loss occurs on continued storage, so that after three months only about 3 per cent of its original potency remains. Analogous results have been obtained with dried potatoes, whereas dried tomatoes (Givens and $\mathrm{M}^{\prime}$ Clugage) appear to retain

1 Chick and Hume, Trans. Soc. Trop. Med. and Hyg., 1917, 10, 141.

2 Lancet, 1918, Dec. 14.

- Delf, Biochem. J., 1918, 12, 416; Delf and Skelton, Biochem. J., $1918,12,448$.

- Various papers in J. Biol. Chem. 
somewhat more of their antiscorbutic properties, and orange juice dried at a lower temperature still more. ${ }^{1}$ Dried vegetables, therefore, although they possess a food value corresponding to the amount of protein, carbohydrate and fat contained in them, cannot be regarded as a substitute for fresh vegetables as regards their antiscorbutic potency.

The effect of cooking on the antiscorbutic accessory is also seriously to diminish its amount. According to Delf cabbage loses 70 per cent of its antiscorbutic efficiency in twenty minutes at the temperature of boiling water. It should be noted, however, that even after this treatment it is more efficacious by far than meat juice or milk. Of special importance is the effect of prolonged cooking, such as is practised on the large scale in camps and institutions as well as in the popular hay box. The effect of lowering the temperature $10^{\circ} \mathrm{C} .\left(18^{\circ} \mathrm{F}\right.$.) is only to diminish the rate of destruction by about 30 per cent, so that after being kept for 40-50 minutes at about $80-90^{\circ} \mathrm{C}$. (temperature of simmering), the same loss would have occurred as would have taken place in twenty minutes at $100^{\circ}$. In practice vegetables are often]" simmered" for several hours and hence lose much more of their antiscorbutic potency than when boiled for a short time. In order, therefore, to preserve as much as

1 Harden and Robison, J.R.A.M.C., 1919, 32, 48. 
possible of this characteristic and valuable property vegetables should be boiled-or, better, steamedfor a short time, rather than stewed for a prolonged period. Further, the addition of soda should be avoided, as it has been shown that the antiscorbutic principle is very sensitive to alkalis. ${ }^{1}$ Canning and preserving also greatly diminish the antiscorbutic value of food-stuffs, and in any circumstances which lead to a restricted diet every effort should be made to include in it fresh vegetables or germinated pulses.

Relation of Experimental to Human Scurvy.It may be concluded with a high degree of probability that the disease produced experimentally in guinea-pigs is the physiological counterpart of scurvy in human beings. This conclusion is supported in the first place by the close general similarity of the symptoms in the two cases, and in the second place by the important fact that the same treatment is effective in curing the disease. Further evidence is afforded by the fact that a similar disease can be produced in monkeys by withholding antiscorbutics from their diet, and that the symptoms produced in this case are again closely allied to those observed on the one hand in guinea-pigs and on the other in human beings, and are, moreover, relieved by precisely the same treatment as is efficacious in these cases. The monkey

1 Harden and Zilva, 1918, Lancet, Sept. 7. 
has indeed proved to be a very suitable animal for experimental work on scurvy, and, since Hart and Lessing's first observations, ${ }^{1}$ has been effectively. employed in the study of the subject. The symptoms produced are strikingly like those of infantile scurvy, and, like these, yield very rapidly to treatment with antiscorbutics. On a diet of boiled rice and milk, both autoclaved, together with steamed wheat germ (to supply the antineuritic and to some extent the fat-soluble factors), the monkey develops symptoms of scurvy in six to ten weeks, the joints, especially those of the hind limbs, becoming weak, the gums spongy and ulcerated with marked haemorrhages, and the teeth loose. Many subcutaneous and subperiosteal haemorrhages are present, and the costochondral junctions of the ribs show marked "rosary" swellings. A monkey in this condition was completely cured by the administration of lemon juice freed from acids (p. 69), which has also been found effective in curing scurvy both in guinea-pigs and babies. Improvement commenced in twenty-four hours, and after five days the animal was almost normal. An examination after two months revealed no traces of scorbutic symptoms.

Susceptibility of Different Animals to Scurvy.A very important point which emerges from the work on experimental scurvy is that different 
animals exhibit very different degrees of susceptibility to the disease. This can be judged in various ways. Thus it has been found that on a diet deprived as far as possible of the antiscorbutic factor guinea-pigs develop marked symptoms of scurvy in 14-21 days, and die in 28-30 days, whereas monkeys only develop the characteristic symptoms in about 6-10 weeks, and human beings in as many months.

Results of the same general character are obtained by ascertaining the minimum dose of an antiscorbutic substance which will preserve the animal from scurvy. Thus Miss Chick and her colleagues have found ${ }^{1}$ that on the average a guinea-pig of $250 \mathrm{~g}$. weight is protected from scurvy by the daily administration of $1 \cdot 5-2 \cdot 5$ cc. of fresh lemon juice, and that a monkey weighing about $2000 \mathrm{~g}$. is protected by practically the same amount of lemon juice $(2.5 \mathrm{cc}$.). Similar results have been obtained by Harden and Zilva (unpublished), who have kept a monkey for a whole year without any development of scurvy by the addition of $2 \mathrm{cc}$. of orange juice to a diet strictly deprived of antiscorbutic factors, whereas the addition of $1.5 \mathrm{cc}$. proved insufficient. The minimum dose of orange juice which will preserve a guinea-pig from scurvy is also about 1-2 cc. We may therefore conclude that the monkey is much less susceptible to scurvy

1 Lancet, 1918, Nov. 30. 
than the guinea-pig (four to eight times) and, arguing from the length of time required for the development of the symptoms, that the human being is again much less susceptible than themonkey.

It is a surprising fact that an animal so closely allied to the guinea-pig as the rat should nevertheless be very much less susceptible to scurvy. To such a degree is this the case that it is commonly supposed that the rat can flourish and produce and rear young in an entirely satisfactory manner and without exhibiting any symptoms of scurvy on diets free from the antiscorbutic factor, such as those used by McCollum and his colleagues in their experimental work on the accessory factors. These consist of purified caseinogen, starch, and salts, with the addition of clarified butter fat and autolysed yeast. It has, however, been observed ${ }^{1}$ that the addition of orange juice to this diet produces a pronounced improvement both in the general condition of the animal and in the rate of growth and the maximum weight attained.

It may therefore be regarded as proved that the antiscorbutic factor is an essential constituent of the diet of the higher animals, the absence of which is in all cases incompatible with the proper development of the animal and may lead to serious lesions and ultimately to death.

1 Harden and Zilva, Biochem. J., 1918, 21, 408, confirmed by Drummond, Biochem. J., 1919, 13, 77. 
Some Practical Applications to Human Diets.Prominent among the antiscorbutics upon which reliance was placed by the old-time seamen were beer and infusion of malt — the sweet wort familiar to the reader of Captain Cook's voyages. Freshly brewed beer, spruce beer and malt,-for the preparation of the sweet wort, were frequently carried as preventives against the scurvy by the ships of the navy and of Arctic explorers, and these materials all seem to have been used with good effect.

An investigation of modern beers and of the malt from which they are prepared ${ }^{1}$ has shown that these are sadly deficient in the antiscorbutic factor. Guinea-pigs receiving malt or a considerable ration of bottled beer or stout were not in any way protected from the onset of scurvy, and the same was true of a monkey which was given, and after some experience appeared to enjoy, a daily ration of about $180 \mathrm{cc}$. of India Pale Ale of an original gravity of 1053, fined and drawn from the wood. This beer is representative of that largely consumed in normal times and was freshly brewed, no sample having been in the cask more than a week or so. If we can accept the experience of Captain Cook and the earlier Arctic explorers as reliable, it would seem probable that the difference between the old and the modern beer may lie in the high

1 Harden and Zilva, J. Inst. Brewing, 1918, 24, 197. 
temperature now employed for the kilning of malt, and air-dried malt and the wort and beer made from it should contain the antiscorbutic principle. This surmise has, however, not yet been put to the test of experiment. The fining of the beer, whereby it is freed from suspended matter, may also be of importance, since, although yeast itself does not contain the antiscorbutic, it is possible that this may be adsorbed in the process of fining and thereby removed from the beer.

Lime- and Lemon-Juice.-The high value of the various Citrus fruits as antiscorbutics has long been appreciated, and for the last century and a quarter reliance has been placed in the navy and mercantile marine on lime-juice as a sure preventive of scurvy. The researches of Miss Chick and her colleagues on the experimental, and of Mrs. Henderson Smith on the historical side $^{1}$ have, however, revealed a very curious state of affairs.

The juice of the lemon (Citrus medica, var. limonum) is much more potent antiscorbutically than that of the West Indian lime (Citrus medica, var. acida) (about four times). When the limejuice is preserved, by the addition of 14 per cent of rum, or of salicylic acid, it loses a considerable proportion of its already small potency and becomes of extremely low value as an antiscorbutic. Hence

$$
1 \text { J.R.A.M.C., 1919, 32, 93, } 188 .
$$


it would appear that the modern use of lime-juice as an antiscorbutic is based on a misconception of the value of this material. How this came about has been elucidated by Mrs. Henderson Smith, and the subject affords a striking example of the danger of making even the smallest generalisation on dietetic questions without a sound experimental basis of fact. In the old days the term "limejuice" was applied to the juice of fruit obtained from the Mediterranean countries, which chiefly comprised lemons, but also probably included the sweet lime (Citrus medica, var. limetta). This juice was highly potent, and it was by its use that the navy was freed from the terrible scourge which had previously devastated it. At a subsequent date, however (about 1866), the West Indian lime was substituted, without experimental enquiry, for the Mediterranean fruits. Scurvy was then no longer to be feared at sea, except in unusual circumstances, such as those of Arctic exploration, and the records show that from that date the official "lime-juice" ceased to be of any value as an antiscorbutic.

It seems probable that the Admiralty in making the change in $\mathbf{1 8 6 6}$ were to some extent influenced by the superior acidity of the West Indian juice, since it was commonly held that the antiscorbutic potency was due to the citric acid which is characteristic of all these juices. It is now known, 
however, that this is not the case. ${ }^{1}$ In fact, the whole of the free citric acid can be removed from the juice-by treating with calcium carbonate and precipitating with alcohol-without any appreciable loss of antiscorbutic power. The solution obtained in this way, after evaporation at a low temperature, has a neutral reaction, and contains only oneseventh of the total solids and one-half of the mineral constituents of the original lemon-juice. It is of great value as a remedial agent (p. 71) and can, by evaporation, be brought to a much higher concentration of the antiscorbutic principle than that of the original lemon-juice.

Milk and Milk Products.-Great interest attaches to the question of the antiscorbutic value of milk and the various preparations now made from it, on account of their supreme importance as food for infants. The breast-fed child depends entirely on its mother's milk for all the accessory factors which are necessary for life, but, since the human organism is apparently unable to build up these essential substances for itself, the mother is herself dependent for them on her diet. Accordingly an adequate provision in the milk can only be maintained when the diet of the mother is itself adequate, and it is of the utmost importance that the diet of pregnant and lactating women should be chosen so as to contain abundance not only of the antiscorbutic

${ }^{1}$ Harden and Zilva, Biochem. J., 1918, 12, 259. 
but also of the antineuritic and fat-soluble accessories. The artificially-fed child depends as a rule on some form of cow's milk. Now cow's milk has been found ${ }^{1}$ to have such a low antiscorbutic value that guinea-pigs, which are protected from scurvy by one gram of cabbage daily, require as much as $100 \mathrm{cc}$. of milk to keep them free from the disease. Further; boiling or drying the milk undoubtedly diminishes its antiscorbutic value, so that infants fed on sterilised milk or dried milk can only be receiving a very small supply of the antiscorbutic value. Medical opinions vary as to the necessity for supplementing a diet of boiled or dried milk with some other source of antiscorbutic, and it is a fact that pronounced scurvy is rarely seen as a consequence of such a diet. It has, however, been pointed out that many children show symptoms of what has been termed latent and subacute scurvy. ${ }^{2}$ These, although not resulting in serious illness, nevertheless constitute a danger to the well-being of the child and are at once relieved by the administration of antiscorbutics. It is impossible at present to say what may be the effect on the child's subsequent development of a partial deficiency of antiscorbutic during infancy, but it is certainly to be avoided if possible. It has recently been shown, for example, ${ }^{3}$ that profound changes in the teeth

1 Chick, Hume and Skelton, Biochem. J., 1918, 12, 131.

2 Hess and Fish, Amer. J. of Diseases of Children, 1914, 8, 385.

3 Zilva and Wells, Proc. Roy. Soc., 1919, B 90, 505. 
are among the very earliest results of a deficiency of the antiscorbutic principle, and these may occur (in guinea-pigs) while the animal is still growing well and is apparently in good health. Whether such effects are also produced in young children, and whether an early deficiency affects deleteriously the subsequent development of the permanent teeth, are questions which have not yet been answered.

The antiscorbutic usually given to young children is some kind of fruit-juice, but it is well to remember that fruit-juices differ very considerably in potency, that of the orange being greatly superior, for example, to apple-juice or grapejuice. ${ }^{1}$ The juice of raw swedes is also of great value in this respect, and can be readily and cheaply prepared.

For use as remedies in cases of pronounced infantile scurvy orange-juice, grape-juice, and " potatocream" (i.e. powdered cooked potato beaten up with milk) are all used. An additional and effective remedy is afforded by the lemon-juice deprived of free citric acid, to which reference has been already made (p. 69). Obtained from a material which has a very high potency, this preparation has the great advantage over others that, owing to its freedom from acid and to the small amount of extraneous matter present, it is tolerated in very large quantities by ailing children and does not cause any

1 See Chick and Rhodes, Lancet, 1918, Dec. 7. 
digestive disturbance. ${ }^{1}$ An account of the effect of this remedy in the treatment of a case of scurvy will serve to illustrate these points and, at the same time, to show the distressing nature of the disease as manifested in young children. The child-a male infantaged seven months-had been fed on sterilised humanised milk from birth and had received the juice of one orange once a week for five months. At $5 \frac{1}{2}$ months the gums were swollen and bled easily, and after another week he began to scream as if in pain when moved. (This is a very characteristic symptom of infantile scurvy.) On admission to hospital the upper gums were greatly swollen, dark purple and fungating, projecting almost between the lips. The edge of the central incisors could just be seen, almost buried in the swollen, projecting gums. The legs were motionless except for movements of ankles and toes. Both legs seemed very painful to touch. There was some recent haemorrhage into vaccination scars and the urine contained red blood cells.

The infant was put upon a diet of undiluted boiled milk, which clinical experience has shown to have no curative effect on scurvy. One ounce of the concentrated preparation, equivalent to double the bulk of original lemon-juice, was given three times a day, i.e. the equivalent of about four lemons daily.

1 Harden, Zilva and Still, Lancet, 1919, Jan. 4. 
Improvement was noticeable in eighteen hours, and the child rapidly progressed to complete recovery. In five days he had taken the equivalent of the juice of forty-two lemons without the slightest disturbance of digestion.

Although the distribution of the antiscorbutic accessory is now becoming well known and the serious character of the effects produced by its absence from the diet are well established and familiar, little progress has been made in the elucidation of the nature of this mysterious principle or of the mode in which it works. These points remain for future investigation, but, thanks to the pioneer work of Holst and Frölich and to its subsequent development in this country and America, we have now sufficient information to enable us to prevent the appearance of scurvy as a disease either in adults or children, and it rests with us to see that this knowledge is effectively applied. 



\section{PHYSIOLOGY IN THE STUDY OF DISEASE}

BY

D. NÖ̈L PATON, M.D., F.R.S.

REGIUS PROFESSOR OF PHYSIOLOGY IN THE UNIVERSTTY OF GLASGOW 



\section{PHYSIOLOGY IN THE STUDY OF DISEASE}

Previous lectures in this course have doubtless made clear to you how the study of physiology, of the human body in action, is the basis of all our knowledge of practical hygiene-the means of keeping healthy.

To-day I wish to show you that it is also the basis of all our study of disease, for disease is simply normal or physiological action gone wrong. What the physician has to find out in every case is simply what has gone wrong, and why it has gone wrong, before he attempts to put it right.

I think that one of the great mistakes in the past has been to study disease without this constant reference to the normal physiological condition. The tendency has been to group a collection of symptoms together and to name it as a disease without full consideration of what the symptoms mean in terms of normal action, or of how they are produced. As a result of this the practitioner of medicine is too frequently content when he has observed the symptoms and given a name to the condition: too seldom does he force himself to 
ask the questions, "What is wrong?" "Why is it wrong?" "Unless he does so the treatment must be merely empirical. Such and such a drug has been recommended by such and such an authority, therefore it is used without any consideration of how it acts in the body or how it can modify the patient's condition.

This way of looking at disease breeds an uncritical spirit which tends to credulity, to seeing things not as they are but as they are expected to be, and to a blind acceptance of imperfectly tested lines of treatment based on superficial and inaccurate observations. Witness the authoritative statements by Dr. This or That on the treatment of influenza or on the action of alcohol!

Few people seem to recognise how much medicine even at the present time is based upon mere empiricism.

Every one who knows about it knows how impotent medical treatment is to cure disease when once established, when once structural changes have occurred.

The slight divergencies from the normal, the slight upsets of physiological action, which are the first stage in the development of real disease are too often ignored. Only when the process has so advanced that organic changes, with the definite train of symptoms which follow them, have appeared is the condition dignified by the name of a disease, 
or does the physician make a diagnosis. If the slight disturbance of action which precedes organic disease were studied from the physiological standpoint, with reference to the question of what structures are working wrongly and why they are working wrongly, medical treatment would have a better chance of success in effecting a cure.

I am not sure that the naming of diseases has not greatly obstructed the advance of medicine. Generally the name is devised from Greek, as at the time of Galen, and as few practitioners understand Greek, this only helps to obscure the nature of the condition, and, at the same time, the extent of their ignorance of its nature.

Thus, if a child's head is enlarged by an accumulation of fluid inside, many are content to say that it suffers from hydrocephalus, which simply means water on the head, but few force themselves in every case of the kind to determine why the fluid should have accumulated there.

But to multiply such examples is unnecessary.

For these reasons it seems that it would be well for medicine if most names of diseases were abolished and if each case were approached from the physiological side with the questions: "What organs are working rightly in the patient?" "What organs are working wrongly?" "Why are they working wrongly?" "Can they be put right, and if so, how?" 
The physiologist spends his life studying the ways in which the activities of the various parts of the body may be investigated, in determining what is the normal action of each of these various parts, how they interact on one another, and how they are modified by various conditions; and he is thus trained to find out if any part is not working rightly, and why it is not working rightly.

So far as regards their relations to medicine, the sciences of bacteriology and of pharmacology are really extensions of physiology, since they involve the study of the manner in which bacteria and their products modify the normal working of the organs, and of the ways in which various drugs influence these vital processes.

Without a training in medicine the physiologist can approach the study of disease with some prospect of success; without a knowledge of physiology the physician is merely groping in the dark.

But, you say, "every medical student has this physiological training." I am afraid that too frequently physiology is studied by the student not as a preparation for the after-study of disease, but as a means of passing a certain examination, too frequently the teacher fails to keep before himself and his students why they are studying physiology, with the result that, when the student comes to the bedside, he does not bring with him 
that training which is all-important in his practical work. This failure on the part of the physiological teacher has been recently emphasised in the British Medical Journal and elsewhere.

But I venture to think that not infrequently the fault lies not with the physiological teacher but with the hospital physician under whom the student finds himself. The physician, after an inadequate study of the science of physiology in the remote past, may have lost all touch and all sympathy with the science of to-day, may have sunk into an easy empiricism, and may be content to cloak his ignorance by sneers at the application of scientific methods to practice.

Such an influence on students is most prejudicial, tending as it does to obliterate the training in scientific methods of study which they have acquired in their earlier years.

Reform is needed in the physiological teacher on the one hand, and in the hospital physician on the other. The one must keep the object of his training of medical students constantly before him; the other must keep in touch with the growing science of physiology, and must welcome all applications of physiological methods to his work.

What is wanted is some one who can show them how these scientific methods are to be carried into practice at the bedside, some one who will keep before the students the necessity 


\section{2}

PHYSIOLOGY AND NATIONAL NEEDS

of applying physiological knowledge to find out what is different from the normal action in every case-in fact, a Clinical Physiologist.

The physiological methods of studying disease cannot better be illustrated than by giving one or two examples.

I shall first take two from our recent war experience, and finally one from ordinary medical practice.

\section{GASSING}

Every one remembers the wave of horror that swept over the country in April 1915 when we heard of the hideous suffering inflicted by the first gas attack by the Germans. When thousands of our poor fellows were brought in, enduring agonies from this new devilment of war, the doctors in charge were faced with something of which they had no knowledge, something which they knew not how to relieve. The first thing was to find to what the distressing symptoms were due, in order that either the cause might in some way be directly counteracted, or that, if the primary disturbance could not be counteracted, some measures might be devised by which the patient might be temporarily relieved till nature had time to re-establish more normal conditions.

Haldane, a physiologist, was sent out. His brilliant researches upon normal breathing and 
the practical application of his results to minerescue work had marked him as the man most likely to be able to determine what was wrong and why it was wrong.

Since his early studies, other physiologists have joined in the investigations, and we soon learned the cause of the various symptoms, and how best the patient may be tided over the most dangerous period.

When a man is gassed with chlorine or with phosgene, a gas which yields chlorine when it has reached the lungs, he is generally found propped up, the face is usually of a dark plum colour, the breathing is rapid, deep, and struggling, and frothy fluid is coughed up. The heart is beating rapidly. The veins of the neck and arms are distended. He is restless and distressed, or he may sink into a drowsy condition. In other cases the lips are blue, the face has an ashy pallor, and the respirations are not so markedly increased. The distress is less, but these are the cases most apt to die.

A knowledge of physiology without any training in medicine explains these symptoms. The dark plum colour of the face is due to the fact that blood not properly supplied with oxygen is coursing in the blood-vessels. We know that blood when properly oxygenated has a bright red colour, giving to the skin its characteristic hue in health. When deprived of oxygen it becomes of a dark purple 
tint. Manifestly, then, these gassed men are not getting oxygen for the blood.

Oxygen is got by the blood from the air in the lungs. Air is drawn in with every breath and reaches millions of little sacs which form the lung, and in the walls of these sacs run the blood-vessels carrying the blood. The blood gives up the carbonic acid it has brought from the tissues, and takes up oxygen from the air in the sacs. The examination of the lung of a patient who has died from gassing at once showed that it is full, not of air, but of fluid.

Manifestly, then, if the air-sacs are full of fluid, the air with oxygen cannot get to the blood, and the patient is drowned as much as if he had fallen into the sea.

But how did the fluid get into the air-sacs?

The study of the application of irritating substances to the web of a frog's foot had long ago shown that one result is a dilatation of all the little blood-vessels, so that they become so engorged with blood that it cannot freely flow away to the veins. As a result of this the fluid part of the blood filters out into the tissues.

Chlorine in the lung acts just in the same way, and the fluid exudes into the air-sacs. Hence this drowning from within; hence, too, this escape of fluid as the patient coughs.

But why the difficult breathing? Why the 
restlessness and the distress and later drowsiness? Why the quick pulse? and why the congestion of the veins? Are these due to different causes or to some common cause?

The work of Haldane and of others had shown that the breathing is regulated by the condition of the blood going to the base of the brain. If the carbonic acid formed in the muscles and passed from them into the blood increases above a certain level, breathing is increased, and thus the carbonic acid is got rid of.

In the case of the gassed patient carbonic acid cannot freely get away, and so it accumulates in the blood and increases the breathing. It is a beneficent response, for the increased breathing helps to overcome the effect of the drowning out of the lung, and not only favours the giving up of carbonic acid, but at the same time helps to increase the taking up of oxygen by the blood.

What of the restlessness and distress and the later drowsiness? Physiological investigations have shown that these are not the result of the increased carbonic acid in the blood, but of a decrease in the oxygen.

It is this want of oxygen which is the real danger. Life is simply a process of combustion for which oxygen is as necessary as it is for a fire, and a decreased supply of oxygen is incompatible with life. 
First it leads to increased excitability of the nervous system, then later to decreased activity, and so to the drowsiness which comes as a relief to the patient, but as a danger-signal to the physician.

Not only is the nervous system thus acted on by the want of oxygen, but the heart also suffers. First its rate is increased, then its action begins to fail, blood is no longer driven onwards, and the patient may pass into the condition of collapse with the ashy grey face and blue lips that so frequently precede death.

Want of oxygen is the prime cause of all the symptoms.

How can this condition be relieved?

Ordinary air contains about one-fifth of its bulk of oxygen. If the air can get freely into the airsacs this proportion of oxygen is sufficient, but if a large number of air-sacs are full of fluid, the best chance is to give a much higher proportion of oxygen to the sacs which are still available, or to enable it to be taken up by the fluid, and which may thus reach the blood.

Inhalations of oxygen were recommended by Haldane on these physiological grounds, and have proved of the utmost value in tiding the patient over this critical stage till the natural drainage from the lungs has removed the fluid from the air-sacs. 
But in many cases the blood is dammed back in the lungs, and the heart gets over distended and cannot drive it on to carry the oxygen to the body. In such a condition the veins are distended with blood, and bleeding by opening one of them relieves the pressure on the heart and enables it to drive the blood onward. This has been found useful in many cases, even although it decreases the amount of oxygen-carrying blood.

Thus you see that a study of the physiology is alone sufficient to elucidate the real nature of the condition, to tell what is wrong and why it is wrong, and to suggest the appropriate line of treatment.

Of course the further question of whether it is possible to render these poisonous gases innocuous had to be tackled. The chemist was called in. It had been found that charcoal has a peculiar action in absorbing and holding on to these gases. It was argued that if air containing these poisonous gases were made to pass through a layer of charcoal, it should be possible to breathe it with safety.

Physiologists, when investigating breathing, had devised methods to enable people and animals to breathe through valves, so as to separate the outgoing from the ingoing air, and these valves had been applied to masks to be worn by those engaged in life-saving operations after colliery explosions to secure them a supply of oxygen. It was thus 
possible to arrange that the air containing the noxious gas should be inhaled through charcoal placed in the inlet to the mask.

Hence chemists and physiologists together devised these gas masks with which every one is now familiar, and which so successfully overcame the dangers of gas attacks.

\section{Wound SHOCK}

Let me now give you another example. You all know how, in the prolonged and monstrous battles of the war, men were stricken down while bathed with sweat or drenched with rain, and you know that, in spite of all the bravery of the bearer companies and the R.A.M.C., it was not possible at once to get them to the dressing-stations.

Sometimes the wound at once led to a condition resembling fainting, in which the soldier became collapsed and senseless. Very often this did not come on at once, but after a time the man became cold, covered with a cold sweat, his skin pale, his face drawn, pinched, and grey, his pulse rapid and feeble, and his breathing quick and shallow. Gradually he might become unconscious and die.

This is the condition to which the name of "wound shock" has been given. What is the meaning of these symptoms? What is wrong, why is it wrong, how is it to be remedied? Fortu- 
nately here nature pointed to some of the measures which should be taken. What the sufferer complained of was thirst and cold; what he craved for were water and warmth.

In slight cases these were sufficient to save life-for the reasons we shall presently discuss, but in many cases they were insufficient, and in spite of them the patient died.

The condition of "shock" or collapse was by no means unknown. Surgeons were already familiar with it in operations, chiefly upon the abdomen, and physiologists had made some attempts to elucidate it.

But now the demand was for definite knowledge immediately. A committee of physiologists was formed under the Medical Research Committee, and in co-operation with physicians and surgeons they got to work. Soon it became manifest that the prime cause of the condition is a failure in the circulation of the blood, so that it no longer carries the all-important oxygen to the tissues of the body. Here again, as in gassing, the danger is death from want of oxygen to the tissues, but in this case not from a failure of oxgyen to get to the blood, but from a failure of the blood to carry the oxygen to the tissues.

1. What is the cause of the failure ?

You all know' that water flows from a point of high pressure to a point of low pressure. The flow 
of blood in the body is maintained by a high pressure being kept up in the vessels leaving the heart, and a low pressure in the vessels returning blood to the heart.

If from any cause the head or pressure of blood in the arteries falls, the flow of blood must be decreased.

From 1733, when the Rev. Stephen Hales made his classical experiments upon the horse, physiologists had done an enormous amount of work upon animals in investigating this pressure-this head of blood,-and they had devised methods and instruments which enabled the pressure to be measured in man without any operative interference.

When these methods were applied in cases of wound shock it was found that there is a marked decrease in the pressure, a decrease which is roughly proportionate to the severity of the symptoms.

To what is this due? The pressure in the arteries is kept up by the force of the pump-the heart-and by the obstruction to the onflow of blood offered by the smaller arteries. If either of these is decreased the pressure will fall.

The experimental work of Starling and his coworkers has shown that the heart is a pump beautifully adjusted to send on just as much blood as comes to it, so that the feeble action of the heart in these cases must either be due to some failure 
in its power of working or to a deficient supply of blood reaching it. That its power of action is not impaired is shown by the fact that if more fluid is supplied to it, it can respond at once by increased activity. Hence we conclude that the low pressure is not due to failure of the heart.

Is it due to a relaxation of the little arteries? These are controlled by the nervous system so that if the pressure in the arteries falls they contract and thus keep up the head of blood so essential for the circulation. Has this mechanism got out of action? It is very probable that, in the early shock or fainting which may immediately follow a wound, it is thrown out of action, but in these later cases no such failure seems to exist.

Why then is there this fall in the pressure? In some cases it is due to loss of blood from wounds, but in many others the loss of blood has been small, and we know from physiological experiments that such a loss is soon made good by the passage of fluid from the tissues to the blood. Of course there might be some interference with this passage of fluid, but that this is not so is indicated by the result obtained on administering fluid which passes into the vessels and raises the pressure for a time. The only possibility left then seems to be that a considerable amount of blood has gone out of effective circulation, that it must have got sidetracked and stored up somewhere. 
Now all through the tissues there is a dense network of minute vessels, the capillaries. We know that these in certain conditions get dilated and that blood tends to stagnate in them. This is well seen in the reddening of the hands or nose in cold weather, a condition which, if it goes on, passes into a blueing, the result of the removal of oxygen from the stagnant blood.

A substance has been found which when injected into the circulation of animals leads to a dilatation of these vessels without any dilatation of the small arteries, and it is a substance which might be formed in lacerated tissues.

Thus, if a considerable quantity of the blood stagnates in the capillaries, the amount in effective circulation will be decreased, so that the amount sent to the heart will be so reduced that its action will be lessened, and the head of blood required to keep up the circulation will fall. As this fall occurs, the force driving the blood through the capillaries will be lessened and the stagnation will increase. But as the blood ceases to flow freely through the lungs, its supply of oxygen will also be decreased and so less blood carrying less oxygen will be taken to the tissues.

This, then, being the explanation of the condition-What is to be done? Manifestly to get up the head of fluid in the arteries so as to re-establish the circulation. How is this to be done? The 
most natural idea would be to inject blood into the depleted vessels. This transfusion of blood has been used for a long time to make good great losses of blood by hæmorrhage. Unfortunately the blood of lower animals cannot be safely used, since it is injurious to the blood of the receiver. It is often difficult to get human blood, and the use of this is also not without danger. Great care must be exercised in determining the character of the blood of the donor. Plain water cannot be used, for it destroys the cells of the blood. But a solution of salt may be made which does not do so, and this has been tried. It certainly raises the blood pressure, but only for a very brief period, because it exudes from the vessels and the patient's condition is not permanently relieved.

Bayliss reasoned that the fluid which must be introduced must resemble blood in its more important physical characters, and must not produce any prejudicial effect. Much time had been spent by physicists and physiologists in the study of what appeared to be matters of purely scientific interest, the exact physical condition of the colloidal state of matter, and of the phenomena of osmosis and of viscosity. From his knowledge of these studies Bayliss drew the conclusion that a solution of gumarabic of a certain strength should fulfil the conditions. He tried it first upon animals, and found that its introduction raised the blood pressure and main- 


\section{PHYSIOLOGY AND NATIONAL NEEDS}

tained it because it did not escape from the vessels; and he found that the feeble heart when given this fluid to contract upon responded and drove it through the tissues, so that the supply of oxygen to them was restored, and recovery was rendered possible, provided the condition of shock had not gone on too long. His method has been applied in the field, and has been proved to be of great service in many cases.

In the light of these observations the patient's craving for water is explained. It is due to there being too little blood in effective circulation, and the free administration of water which is in part absorbed into the blood serves in slight cases to raise the blood pressure sufficiently to allow of recovery.

The sense of cold is due to the stagnation of the blood-the warm blood from the interior is not sent to the skin, where alone are placed the nerve structures which when stimulated give us the sense of cold.

Physiologists have thus explained the main disturbance involved; and although their evidence of the accumulation of blood in the capillaries cannot be considered conclusive, they have been able to suggest a line of treatment which has proved of the greatest service.

The first example I have given shows how by the investigation of physiologists the cause of the 


\section{PHYSIOLOGY IN THE STUDY OF DISEASE 95}

condition was made clear, and the proper treatment indicated.

The second example shows how the work of physiologists proved the essential nature of the condition and pointed out the line of treatment, but has still definitely to solve some parts of the problem.

Let me now give an example of how physiological study has advanced our knowledge of disease, but has so far failed to clear up the problem completely or to discover the method of treatment. It has given us an advanced post from which further progress should be possible.

\section{Tetany}

Few of you have heard of the disease tetanynot tetanus, a very different condition. It chiefly affects young children, and very specially those suffering from rickets. In an investigation into the social conditions associated with the development of that still mysterious disease, Miss Ferguson found no evidence of tetany in any of the nonrickety children studied, while it was or had been present in $\mathbf{4 2}$ per cent of the children with rickets.

When fully developed, tetany is characterised by a peculiar rigidity of the muscles chiefly of the hands and feet, which leads to the hand being fixed in a peculiar position and to the feet being strongly bent with the toes pointing downwards. The other 
muscles of the arms and legs may be affected. The muscles of the larynx are also sometimes in spasm and cause a peculiar crowing sound in breathing, especially when the child cries. Frequently the condition goes on to the development of general convulsions, in one of which the child may die. The condition may be latent for long periods, but it may then be detected by the fact that the nerves and muscles are peculiarly excitable-so that a tap on the side of the face will cause a characteristic spasm at the angle of the mouth, while an electric current produces a peculiarly exaggerated effect when applied over the nerves or the muscles.

A somewhat similar condition is sometimes found in adults of certain districts, more frequently attacking those engaged in sedentary employment, such as shoemakers.

Many different theories have been from time to time advanced as to the cause of the condition, since Clarke first described it in 1815 ; but the first important light was thrown by Austrian and Swiss surgeons when the operation of removing goitrestumours of the thyroid gland-came into vogue.

They found that a certain proportion of the patients after operation suffered from a condition of tetany. This they thought to be due to removal of the thyroid gland. But closely associated with the thyroid are little structures which from their position have been called the parathyroids, and 
certain Italian physiologists first proved that it is the removal of these and not of the thyroid which is followed by the symptom of tetany.

When in 1913 I was writing upon the various structures which, like the thyroid, regulate the chemical changes in the body, I was struck by our ignorance of the functions of these parathyroids and of the want of knowledge of how their removal caused this peculiar condition.

This set me to work to try to find out, and in this investigation I was joined by Dr. Leonard Findlay of the Royal Hospital for Sick Children, Glasgow, and by various members of the Staff of my Laboratory. It gives me pleasure to acknowledge the financial help given by the Medical Research Committee in the prosecution of these investigations.

As the result of our experiments we were able to show that, after removal of the parathyroids from animals, some injurious or toxic substance develops in the blood and causes the symptoms, and that if the animal be bled and salt solution run into the circulation the symptoms disappear for some time, but recur. This observation had been previously made by Macallum. We found that the spasm of the muscles is due to increased excitability of the nerve-cells in the spinal cord from which the nerves to the muscles take their origin, but that, on the other hand, the increased response of the nerves and muscles to mechanical or electrical 
stimulation is due to some action in the endings of the nerves in the muscles. The two are independent of one another, and one or other may be more marked.

We had next to try to discover what this toxic substance with these peculiar actions might be. Evidently it was something developed in the body either only after the parathyroids are removed or to a greater extent than usual after the ablation of these structures.

In the laboratory at this time another set of investigations were in progress, upon the significance of a substance found in muscle, a substance, which is itself not poisonous, but which when broken down yields a poisonous substance known as guanidin. This guanidin also occurs built into all living tissue in a harmless combination.

Well, we discovered that the administration of guanidin produces in animals the symptoms of tetany.

But this was not enough; we had to show that in the tetany produced by removing the parathyroids from animals, and in the spontaneous tetany of children, the amount of guanidin in the blood is increased.

This Burns and Sharpe demonstrated to be the case, and thus it would seem that tetany is due to the liberation of this substance, and that the parathyroids somehow control its production. 
How the parathyroids act we do not know, and whether they alone control the production of guanidin we do not yet know.

But our work has pretty clearly shown that these various forms of tetany have some common origin, and that in all probability a defective action of the parathyroids is the cause of the condition.

Till we know more of the essential nature of the changes in the body which lead to the liberation of guanidin, to suggest lines of treatment is hopeless. We must simply go on investigating till the secret is wholly revealed.

The study of tetany is, I think, a good illustration of the way in which laboratories and hospitals should be combined for the study of disease. The combination has been too rare in the past, but there is, I think, a growing recognition of the fact that in this way alone can our knowledge of disease be increased. It is the man trained as a physiologist who is prepared to devote his whole time to the study of disease in the wards of the hospital, who is of real use in advancing knowledge and in training students to carry on such work. Provision must be made to relieve such men of the necessity of devoting a large part of their time to general and consulting practice as a means of making a livelihood. An adequate wage must be provided for them.

I have tried to show you how physiology and a 
physiological training may be used in the advancement of medicine. But it must be distinctly understood that the study of physiology must be undertaken in no utilitarian spirit.

The object of the physiologist must be to attempt to solve all the problems of the way in which living matter acts without considering whether the knowledge may be of use to humanity. At present I fear there is a great tendency to insist that all investigations shall have a utilitarian object; but , all experience has shown that most of the important advances in the application of science to medicine have been based upon investigations which primarily seemed to have no direct bearing on the well-being of mankind.

The application to practical surgery by Lord Lister of Pasteur's apparently purely academic researches in the origin of life are well known to every one.

- I have already referred to the apparently unprofitable study of the colloidal state of matter, of viscosity and of the process of osmosis-none of which seemed to have any possible bearing upon human welfare; and I have shown how in the hands of Bayliss the knowledge thus gained was applied to the treatment of "wound shock."

When Galvani started his research on the electrical phenomena of muscle and subsequent physiologists carried these on, who would have 
thought that it would ever be applied to the diagnosis and prognosis of disease of the heart ?

You may perhaps wonder that people exist who can devote their lives to the investigation of what appears to have no direct utility. Fortunately such people do exist, people imbued with the spirit of curiosity, with an insatiable thirst for knowledge for its own sake, and quite apart from any possibility of its being found useful.

To them the pursuit of knowledge is what hunting is to the hunter, 'and fishing to the angler. It absorbs all their energies, and in the difficulties to be contended with they find their chief joys. Were it not so the life of scientific investigators would be incomprehensible. The difficulties are enormous: the disappointments sustained are endless, and the prizes secured usually but small when compared with the time and labour expended. What the general public have to grasp is that knowledge is power, power to enable us to live better under the adverse forces against which we have to contendthat there are a certain number of individuals who are born hunters after knowledge, and that it is to the advantage of mankind to give them every facility for the prosecution of their hunt without demanding that a utilitarian goal shall be in sight.

"Ignorance is the curse of God: Knowledge the wings with which we fly to Heaven." 



\section{THE CONSERVATION OF OUR}

\section{CEREAL RESERVES}

BY

ARTHUR DENDY, D.Sc., F.R.S.

PROFESSOR OF ZOOLOGY IN THE UNIVERSITY OF LONDON 



\section{THE CONSERVATION OF OUR CEREAL RESERVES}

IT may appear at first sight that the subject of this lecture is of an economic rather than a physiological nature and that it is accordingly somewhat out of place in the present series. A moment's reflection, however, will serve to convince you that this is not the case. Indeed, the problem before us-how best to conserve the cereal reserves of the Empire -is one which can be solved only by an adequate knowledge of the physiology of a considerable number of distinct organisms, some of them plants and others animals, apart altogether from the fact that its importance depends entirely upon the physiological requirements of the human body.

On the one hand, I would remind you that a grain of wheat, or maize, or any other cereal you may like to name, is a living organism, a seed, containing an embryo plant, which, though dormant so long as the grain remains dry, is capable, under the influence of moisture and warmth, of resuming an active life. Even in the dormant condition its vital powers are not entirely suspended, and destructive meta- 
bolism, involving the absorption of oxygen and the production of carbonic acid gas, or carbon dioxide, continues for a very long time even while the grain remains ordinarily dry.

On the other hand, the damage to which stored grain of all kinds is subject is very largely, if not chiefly, due to the activity of other organisms, insects of various kinds, mites, moulds, and probably bacteria, to say nothing of rats and mice, which are more easily recognised and dealt with. A knowledge of the physiological processes going on in the grain, combined with a knowledge of the physiological requirements of the numerous organisms by which it is attacked, is clearly essential to the correct understanding and ultimate solution of our problem.

The zoologist and the botanist must also be consulted as to the systematic position and life-histories of the organisms concerned, and, no less, the architect and the engineer, when it comes to a question of constructing granaries and so forth. The problem has also, of course, its economic and commercial sides. I need hardly say that I do not profess to be capable of dealing with all these very different aspects of the question, and it is chiefly with regard to purely biological matters that I venture to ask your attention. At the same time I hope to be able to convince you that the conclusions at which we have already arrived are by no means devoid of importance from the strictly utilitarian standpoint. 
I shall even venture, at the close of this lecture, to make some practical suggestions which may perhaps be found worthy of consideration by practical men.

It is unnecessary to insist upon the fact that mankind is to a very large extent-one might say almost entirely-dependent upon cereals of various kinds for those supplies of carbohydrates so necessary for his existence. We know that even in prehistoric times cereals were cultivated. As regards the most important of them-wheat-the great botanist, De Candolle, tells us that "The manifold names of ancient languages must, therefore, be attributed to the extreme antiquity of its culture in the temperate parts of Europe, Asia, and Africa -an antiquity greater than that of the most ancient languages," and that the Chinese, who grew wheat 2700 years before the commencement of the Christian era, considered it a gift direct from Heaven.

The storage of cereal reserves for future use is also a very ancient custom, originating no doubt in the obvious necessity for making supplies last over from one harvest to the next. At the present day it is frequently necessary to store our cereals for much longer periods than this. Certain communities no longer depend entirely upon locally grown grain. Certain countries are much better suited for cereal production than others and supplies have to be transported from the country of origin to the place where they are to be consumed. Storage 
therefore becomes necessary in the country of origin while awaiting shipment, and in the country of consumption while awaiting distribution to the consumer. It may also be desirable to keep large reserves on hand in case of emergency, for crops may fail or a long war may interfere both with local cultivation and with the supply of grain from overseas. In Australia recently, for example, it is said that no less than 28 million pounds worth of wheat was held up for want of shipping, and owing to the absence of proper storage accommodation a large part of it was either completely destroyed or very seriously damaged. In time of war any country which does not grow enough cereals for its own needs may become dependent upon stored reserves, a fact which has recently become familiar to all of us by bitter experience of what may take place when no adequate supplies have been accumulated. - Let us hope that we shall never again find ourselves in such a precarious position.

The conservation of our cereal reserves, whether in the form of dry grain or of manufactured products, such as flour and biscuits, is therefore, from many points of view, a matter of extreme national importance, and the problem of the best method of storing such reserves is at present attracting some attention, though perhaps not so much as it deserves.

Professor Halliburton has already told us some- 
thing of the work done by the Royal Society during the war in relation to food. He left it to me to speak to you of their Grain Pests (War) Committee, which, to quote from the Introductory Note to their first Report, "was appointed by the Council of the Royal Society in June 1916, as the result of a correspondence with the Board of Agriculture and Fisheries, in which the Board requested the Royal Society to appoint a Committee "in relation to the damage done to grain by insects." " It was as a member of this Committee that I first became interested in the grain problem. Much work has already been done by members of the Committee and by assistants paid by the Royal Society. I would call attention especially to the valuable Report by my colleagues, Professor R. Newstead and Miss Duvall, on the mites which attack grain and flour. My own attention was at first directed to the habits and life-histories of the various small beetles which occur in stored wheat and the damage which is due to their activities, but I was gradually led on to take a wider view of the subject and to make a number of experiments with regard to methods of preventing their ravages. These led me to consider the problem of the storage of cereals as a whole.

It soon became evident that I had undertaken more than I could carry out single-handed, especially as the work had to be done in the intervals of my ordinary professorial duties. Some of the problems 
involved were also of a chemical nature, quite beyond the limits of my own capacity, and it became necessary to secure the services of a properly trained chemist. The generosity of the Royal Society enabled me to do this, and I was fortunate enough to find in my colleague, Mr. H. D. Elkington, the right man for the purpose. I may say at once that much of what I am able to tell you to-night is the result of Mr. Elkington's enthusiastic co-operation.

The dangers to which stored cereals are liable may conveniently be classified under four heads, (1) the attacks of rats and mice, (2) the attacks of insects and mites, (3) the attacks of moulds and bacteria, and (4) the process known to the trade as "Heating."

As to the rats and mice I need say nothing. The danger from this source is completely eliminated by any rational method of storage, and though the loss in this connection is undoubtedly still enormous, its prevention would seem to be a matter for legislation rather than for scientific investigation.

Of the insects, on the other hand, I might say much, for there are many different kinds involved in the problem and on each one a volume might be written. The best-known and the most destructive, at any rate in temperate climates, are the grain weevils, Calandra oryzae and Calandra granaria, but in India two other beetles, Rhizopertha dominica and Trogoderma khapra, are also very serious pests. 
Then there are the larvae of various moths, such as Ephestia elutella, and a number of secondary pests - mostly small beetles-which do little or no damage to sound grain, but feed upon the debris resulting from the ravages of other species.

The ignorance of those engaged in the grain trade with regard to these insects is, perhaps, in the present state of national education, notaltogether surprising. Few, if any, of those whom we have met seemed to know that there is more than one kind of weevil, or that a weevil differs from the other kinds of beetles, or that the "maggots" or larvae found in the grain have anything to do with the moths which are found flying about the granary. Indeed it was seriously suggested to us in one warehouse which we visited that the moth larvae, which were crawling over the heaps of grain in countless thousands, might be derived from mites! The very small size of all these insects has no doubt a good deal to do with the fact that so little is known about them by those who have the greatest opportunities for observing them. A little knowledge of their habits and lifehistories - intensely interesting in itself - would, however, be a valuable asset in the hands of those whose duty it is to inspect and supervise warehouses where vast quantities of provisions of all kinds may be stored. We have found, for example, that there is actually a widespread and strongly rooted prejudice in favour of moth larvae, or at least of the 
web which they sometimes spin over the heaps of grain, it being asserted that the grain under such a web is always in good condition. However this may be, there can be no doubt, not only that the larvae actually do a certain amount of damage to the grain itself, but also that their presence in a warehouse must be a source of danger to other food products stored in the same or adjacent buildings. In the case which we investigated, where hundreds of thousands of " maggots" were crawling over the grain and the adjacent woodwork, we found that the moth of which they were the larvae, and which was also to be found in the granary in the adult state, was the notorious Ephestia elutella, which is known to infest almost any kind of food substance, from grain to chocolate. Here was a breeding-ground from which the insects might spread in thousands over a large area, with disastrous consequences, and this danger was apparently quite unrecognised by those in charge.

Unfortunately time does not permit of my saying much about the habits and life-histories of the various grain insects, but we may pause for a moment to consider their effect upon the grain. Let us confine our attention to the weevils. The amount of damage which these little creatures do is of course directly proportional to their numbers, and these depend upon their rate of multiplication. We have made more than 90 experiments to determine 
this rate under various conditions of temperature and moisture. Some of our results may interest you.

A single pair of rice-weevils (Calandra oryzae), isolated on April 23rd, 1918, and kept in wheat in a moist incubator, at an average temperature of $28^{\circ} \mathrm{C}$. $\left(82.5^{\circ} \mathrm{F}\right.$.), increased in 29 days to 6 live adults, in 48 days to 19 , in 69 days to 113 , in 97 days to 758 . All loose weevils were then removed and in another fortnight 653 more live adults were found amongst the grain. Thus in 111 days-almost exactly 16 weeks-a single pair of these insects had multiplied about 700-fold.

At ordinary laboratory temperatures, with the room only slightly heated in cold weather during the daytime, and not at all on Sundays, the rate of multiplication is of course much slower, and indeed multiplication only takes place during the warm months. For example, 100 rice-weevils were placed in 130 grammes of wheat on April 5th, 1918. On May 14th only 28 live adults were left, on June 11th only 20 , on July 1st, 20 ; but by August 13th the number had increased to 382 , and by October 5 th to 749 .

The most satisfactory experiments made with the other species of grain-weevil (Calandra granaria) at room temperature gave a higher rate of multiplication, but again only during the warmer months. One hundred adult weevils were placed in $\mathbf{5 0 0}$ 


\section{4}

grammes of wheat on April 10th, 1918. By July 15th the number of live adults had dropped to $80,{ }^{1}$ but by September 3rd it had increased to 2203 . This species is generally believed to be indigenous in countries with cooler climates than those of which the rice-weevil is a native, and is accordingly more likely to become troublesome in Great Britain under ordinary temperature conditions.

It is quite clear from these results that in our own climate multiplication only takes place in the warmer months of the year-except in places that are artificially heated-hence one of the reasons for keeping grain-stores as cool as possible. In warm weather, however, it is obvious that the rapid multiplication of the weevils is a source of great danger, and the danger is naturally greater in climates like those of India, Australia, and South America.

There can be no doubt that a certain amount of moisture in the wheat-say from 8 to 16 per cent or thereabouts-is also necessary for the maintenance of the weevils in a flourishing condition, and much stress has very properly been laid upon the importance of keeping the wheat as dry as possible in order to prevent "weevilling." Unfortunately, however, wheat is a very hygroscopic substance and readily absorbs moisture in damp weather, so that the problem of keeping it dry is not altogether a simple one, while, on the other hand, the weevils

1 Possibly 83, as only 17 were found dead. 
may, remain alive for a long time in dry wheat, ready to resume a more vigorous existence when the necessary moisture is forthcoming.

The effect upon the wheat of a large number of weevils living under favourable conditions is very remarkable. The adult females lay their eggs in small punctures in the grains. The young larvae, hatching from these eggs, bore their way deeply into the grains, and there undergo their complete development, gradually hollowing out the grain as they feed, and finally eating their way out as perfect insects. The adult lives for a long time and feeds voraciously, and the combined efforts of adults and larvae rapidly destroy the grain. In addition to this direct effect there is an indirect one, which, at any rate in a moist atmosphere, may be of great importance in completing the work of destruction. As they feed, the weevils produce large quantities of excrement, and not only does this foul the grain but it appears to attract large quantities of moisture and forms a substratum for the growth of mouldsand doubtless also of bacteria-by the action of which the remainder of the grain is presently converted into a black, decaying mass, resembling old stable manure and giving off large quantities of ammonia. In spite of the presence of the ammonia weevils continue to live in the upper and less affected layers of such a sample for a very long time.

You may perhaps say: "It's all very well to 
breed vast numbers of weevils in the laboratory, under exceptionally favourable conditions, but do these insects ever occur in sufficient numbers under normal conditions of storage to render the problem of their extermination really serious?" This very legitimate question can, without the slightest hesitation, be answered in the affirmative. My colleagues and $I$ have examined a great many samples of wheat from various parts of the world and found a very large proportion of them to be "weevilled" to a greater or less extent. We have had a parcel of badly infected wheat delivered at my laboratory which dripped weevils as it was carried aboutthis, however, had been specially selected for us. On the other hand, many samples which are believed to be free from weevils show on incubation that they are really infected and weevils emerge from the grains in the course of a few days or weeks. This is a fruitful source of error which has to be guarded against in experimental work. Weevilling often becomes greatly intensified in the course of a sea voyage, owing to the warmth and moisture encountered in the tropics, and the cargo on reaching this country is sometimes in a deplorable condition.

It is no easy matter to estimate the actual amount of damage due to weevilling. Noël Paton, however, in his Indian Wheat and Grain Elevators, published in 1913, tells us that " one of the largest shippers of Indian wheat has said that the average wastage 
from this cause is about $2 \frac{1}{2}$ per cent." This may be an underestimate, for in the United States of America, with their cooler climate, the damage to the cereal crops while in storage has been estimated at 5 per cent. In any case it is serious enough, and must probably amount to many millions of pounds sterling per annum throughout the world.

We come next to our third category of danger to which stored grain is liable, viz. the action of moulds and bacteria. Under normal conditions and with reasonable care in keeping the wheat dry, however, there appears to be little to be feared from this cause, and in any case I have no data to put before you. I mention it merely because I shall be able to show later on that it may be avoided by the same means as those to be recommended in the case of more serious dangers.

It remains to speak of the danger that arises from heating, which appears to be a more serious matter in the eyes of the grain trade even than the weevilling problem. It is a danger which arises when large quantities of grain are stored with too high a percentage of moisture, and it is of course by no means confined to wheat. It is therefore necessary to take the temperature of stored grain at frequent intervals and to turn over the heap as soon as it becomes dangerously warm.

A very valuable paper on the subject has recently 
been published in the American Journal of Agricultural Research ${ }^{1}$ by Messrs. Bailey and Gurjar. These authorities accept the view "that the phenomenon known as respiration is responsible for the heat energy released in a mass of damp grain." Unfortunately botanists use the term respiration in an extraordinarily wide sense, including thereunder all the complex and varied processes of destructive metabolism, so that it becomes impossible to distinguish between respiration and fermentation. Messrs. Bailey and Gurjar, however, clearly exclude microbic fermentation as a cause of the heating of grain. In the same paper they tell us that "spontaneous heating in damp grain is occasioned by the biological oxidation of dextrose and similar sugars, chiefly in the germ or embryo of the kernel." The term "biological oxidation" is perhaps less objectionable than "respiration," though it may well be questioned whether biological oxidation can be distinguished from chemical oxidation.

Apart from theoretical considerations, however, the paper referred to contains much valuable information as to the conditions under which "heating " takes place. The most important determining factor is obviously moisture. The increase in the rate of the so-called "respiration" is slow and gradual until the moisture content of the grain reaches some 13-14.5 per cent, after which it becomes

1 Vol. xii. No. 11, Washington, March 18, 1918. 
markedly accelerated. Increasing temperature also causes increase in the rate of "respiration" until $55^{\circ} \mathrm{C} .\left(131^{\circ} \mathrm{F}\right.$.) is reached. Accumulation of carbon dioxide decreases the rate of "respiration." "Respiration" is also reduced in an oxygen-free atmosphere, the ratio to that occurring in a normal atmosphere being about 1-2.5. I need not remind you that the rise of temperature-or heating of the grain-depends upon the rate of "respiration," or, as I should prefer to put it, upon the rate at which destructive metabolism takes place.

Their knowledge of the physiology of the organisms concerned, imperfect though it still is, has enabled scientific experts to suggest various ways of combating the diseases to which stored grain is subject. Insect-infested grain can at least temporarily be cured by fumigation with poisonous gases of various kinds, such as carbon disulphide, hydrocyanic acid, and carbon dioxide. A better and safer method, now much used in America, depends upon the extraordinary susceptibility of grain insects to changes of temperature. Professor Chittenden pointed out more than twenty years ago that a temperature of from $125^{\circ}$ to $140^{\circ} \mathrm{F}$., continued for a few hours, is fatal to grain insects, while wheat can be subjected to a temperature of even $150^{\circ}$ or more for a short time without destroying its germinating power. The heat may be applied by means of steam pipes, whereby the whole of the building 
in which the grain is stored may be raised to the required temperature, or badly infected grain may be put through special cleansing machinery and heat applied at the same time. I understand that the latter plan was very successfully employed by my colleague Professor Maxwell Lefroy, who was sent out to Australia by the Royal Commission on Wheat Supplies to find out the best method of dealing with the enormous stocks of wheat accumulated there under most unfavourable conditions during the war. Apparently the time necessary to effect the destruction of the insects at a temperature of $145^{\circ} \mathrm{F}$. is very much less than used to be supposed, for Professor Lefroy is reported to have said, in a lecture delivered recently at the Royal Institution, that a temperature of $145^{\circ}$ applied for three minutes killed anything.

Apart altogether, however, from the actual loss due to the attack, all curative methods are both expensive and troublesome, and what is urgently required is some practical method of storage which shall render the grain absolutely safe from deterioration for a large number of years-to whatever cause such deterioration might be due. All theoretical considerations seem to point to air-tight storage in properly constructed granaries as the ideal plan. Moreover, this method, or a reasonably close approximation thereto, has been very widely employed from time immemorial amongst primitive races 
of mankind-I refer of course to the use of underground pits, constructed of earth, rock, or masonry.

Unfortunately. I have not time to say as much upon this interesting topic as I should like to do, but I wish to put before you some facts with regard to the practice as it exists on the one hand in India and on the other in Malta.

Thirty-one years ago Mr. E. C. Cotes published a memoir on the Wheat and Rice Weevils in India (1888), in which he brings together much valuable information collected from native sources. I select the following quotations from the evidence: "Wheat stored so as to be practically air-tight is said to be free from the attack of weevils. The method which seems to have been widely adopted in India is as follows: Holes are dug in the ground, or round buildings of mud are erected, the floor and walls in each case being lined with chaff or sand, and the grain covered with a layer of the same material, the whole being covered in with closely packed earth. Wheat so stored for three years has been found, on opening, to be quite sound."

"Natives do not care and do not bother their heads about weevils, knowing that in their airtight pits underground nothing will attack the grain."

"The only method to prevent destruction of grain from the weevil is to make the granary air-tight." 
That this method, valuable as it doubtless is in careful hands, is not always carried out properly is clearly indicated by Mr. F. Noël Paton, DirectorGeneral of Commercial Intelligence in India. Writing in 1913, in Indian Wheat and Grain Elevators, he says: "Quantities of wheat are still stored in pits. These are lined with straw and chaff, and sometimes, it is said, with a plaster compounded of mud and cow dung. The wheat is placed in them in bulk and is covered with straw, earth and thatch. Protracted storage in such pits results in damage more or less serious. This damage appears in the form of moulds and results in discoloration and bad smell. But there is evidence that the ravages of weevil are to some extent inhibited by the conditions set up. This is believed to be due to the generation of carbonic acid gas in the processes of decomposition. It is well understood that it is dangerous to enter such pits when they are first opened; and there is on record at least one authenticated case of a dealer being convicted of a rash and negligent act which occasioned the death of several labourers sent into.a pit prematurely."

The same principle of storage is carried out in a much more thorough and efficient manner in Malta, where, as Professor Zammitt tells us in a letter addressed to Professor Newstead, one of my colleagues on the Grain Pests Committee, the granaries have the form of deep pits made in the ground, 
the wall of the pit being composed of rock or masonry and the interior lined with dry straw. "The air within the granary becomes very heavily charged with carbon dioxide, as a result of the ordinary process of respiration by the grain, and before removing the grain the granary must be thoroughly ventilated by an air-pump or fan. The carbon dioxide acts very effectively as an insecticide, so that in a properly constructed granary, water-tight and air-tight, no insect can develop." "Grain thus stored can be kept indefinitely, the only evil effect of long storage being an impairment of the germinating power, which becomes torpid and irregular, if the grain is stored for more than two years. At the same time the bread-making quality of the grain is improved, i.e. the bread-paste (dough) is more readily affected by yeast. Fermentation cannot take place unless the grain is heavily charged with moisture, from exposure to rain, or infiltration of sea-water on board ship."

It is somewhat remarkable that, with so much evidence in its favour, the method of air-tight storage should never yet have been scientifically elaborated and put into practice on a large scale in any of the great grain-producing or grain-consuming countries of the world. It is to be feared that scientific men themselves are partly to blame for this state of affairs. On the one hand a most curious belief has 


\section{PHYSIOLOGY AND NATIONAL NEEDS}

long been current in entomological circles with regard to the ability of weevils to withstand almost any amount of absence of ventilation, and, on the other hand, a very natural prejudice exists in the trade itself in favour of ventilation to prevent the grain from heating-reasonable in so far as it recognises that ventilation serves to carry off heat and moisture, but leaving out of account other considerations of much greater moment.

As to the alleged capacity of grain-insects to live and flourish. without ventilation the most precise statements have been furnished by one scientific writer. He tells us that "a non-ventilated atmosphere at about $80^{\circ} \mathrm{F}$., eharged with water vapour (no matter how poor in oxygen, and contaminated with carbonic acid gas), provides the most favourable conditions for the life and reproduction of these weevils." Again: "Hence almost any accumulation of $\mathrm{CO}_{2}$ in the atmosphere in which the weevils are living may be disregarded as a preventive agent"; and, once more: "In the face of these and my other results it would be absurd to hold either that weevils require a free play of air, or even that free access to air, when possible, is favourable to their existence." In face of such statements as these, how could any one feel much confidence in recommending air-tight storage as a prevention of weevilling?

It was obviously necessary that the matter should be set at rest once for all by a series of 
scientifically accurate experiments which left no loophole for argument. Improbable as it might seem to a physiologist that any ordinary insect could exist for any considerable length of time in an atmosphere devoid or almost devoid of oxygen gas, yet the contrary belief with regard to these weevils was widely spread, and it.had to be got rid of.

Fortunately this was a very simple matter. It is only necessary to seal up grain containing live insects in glass jars or cylinders with suitable stoppers, fixed on with paraffin wax, in order to convince oneself that no insect can withstand such treatment. The experiment has been tried repeatedly in my laboratory, under various conditions of temperature and moisture and with nine different species of grain insects, including the two weevils. It was also tried with mites. Not only do all species succumb to such treatment sooner or later, but, unless a relatively very large air-space be present, they do so in a remarkably short time-as soon, in fact, as nearly all the oxygen present has been replaced by carbon dioxide. The actual time required to effect this depends upon the proportion between the number of insects, the amount of grain and the volume of air present at the commencement of the experiment, as well as upon temperature and moisture.

I may add that we have proved beyond question that the hermetical sealing of badly infected grain 
completely sterilises the wheat as regards insect life, so that the weevils must be killed by this treatment at all stages of their development.

In Nos. 1 and 3 of the Reports of the Grain Pests (War) Committee of the Royal Society we have published details of twenty-seven different experiments of this kind, sufficient, we hope, to discredit for ever the remarkable physiological powers attributed to grain insects.

It is worth while pausing for a few moments to consider the origin of so widespread a belief. People talk glibly about air-tight bottles and hermetically sealed tins, and will open such bottles or tins and show you live insects in them, but if you ask them how they know them to be air-tight or hermetically sealed you will probably either get no answer or be told that some inspecting authority has passed them as "intact," which seems to mean little more than that they have not been opened. We have been informed by an Army Depôt officer that tins of army biscuits are described as "intact" even if they have split seams-provided the lid has not been touched; and the assumption that "intact" and "hermetically sealed" mean one and the same thing is clearly responsible for the statement that the larva of the much-dreaded flour-mothEphestia kuehniella-works its ravages in hermetically sealed tins of army biscuits.

A few months ago the same officer brought me 
six one-pound tins of pearl barley, part of a lot which had been in store since 1914 and had recently been condemned for weevilling. They were beautifully made tins, soldered with great care, and certainly they looked as if there could not be much wrong with them. One had already been opened, however, and there could be no mistake about the live weevils. The remaining five I plunged into hot water, and, much to my gratification, four of them bubbled at the seams, showing that the soldering was imperfect . and they were not really air-tight. The fifth tin, however, appeared to be perfectly sound, and I need hardly say that it contained no live insects. It was quite evident that a weevily sample of barley had been sealed up and that weevils had been able to maintain themselves for four years in some of the tins in which the soldering had been imperfect.

It must be remembered that an imperfectly closed vessel, such as a tin can, itself "respires," to use a much-abused word in another of its many senses, to some extent like a human being. Changes of temperature and pressure pump air in and out of any small opening, so that the oxygen supply in the interior is constantly being renewed. The same process is responsible for the appalling accumulation of dust that takes place in closed drawers in London. The incoming air is laden with dust particles which are deposited before the air is replaced by a fresh dust-laden supply. 
Thus it is evident that a very minute aperture in a tin or other receptacle may be quite sufficient to maintain a number of insects in a healthy condition in the interior, and to give rise to the belief in their independence of ventilation.

We have here, if I may venture to say so, an admirable illustration of the fundamental importance of scientific accuracy. You must not assume that a tin or other receptacle is hermetically sealed until you have proved it to be so, or you may be led to utterly erroneous conclusions.

We may then take it as definitely established that insects cannot continue to live in air-tight receptacles, and from this point of view at any rate the storage of grain in air-tight granaries is fully justified on scientific grounds. I may also tell you that our experiments have shown that the growth of moulds is prevented in exactly the same way; for if two jars of wheat are taken, each kept moist by a supply of water in an inner tube, and one be sealed and the other ventilated, both being kept in a warm incubator, the wheat in the ventilated jar will become mouldy in the course of a few weeks while that in the sealed jar will not.

We come next to the important question--What is the effect of air-tight storage upon the phenomenon known as " heating"? It might very naturally be supposed, from the care which has to be taken to prevent this process from taking place under existing 
conditions of storage by means of ample ventilation, that air-tight storage, unless the grain were thoroughly dry, might lead to disastrous results, and indeed this objection has actually been raised in opposition to our views. If, however, you have followed what has been said as to'the nature of heating and how it results from the processes of destructive metabolism which go on in damp grain -the so-called "respiration"-you can hardly fail to realise that the probabilities are that air-tight storage will prevent heating just as it prevents the attacks of insects and of moulds. For destructive metabolism implies combustion, for which a supply of oxygen gas is necessary, and, apart from the question of anaërobic fermentation, which ought certainly to be investigated, but which does not seem at all likely to lead to serious results, the amount of damage which is possible must be directly proportional to the amount of air supplied. We cannot, however, content ourselves with mere theory in a matter of such vital importance, and the first question that has to be answered definitely one way or the other is this-Does grain, even when in a moist condition, undergo heating when hermetically sealed up or does it not?

Of course, in actual conditions of storage, heating only takes place in relatively large masses of grain, in which the heat produced can accumulate to the necessary extent. The same result may, however, 
be brought about in quite a small quantity if precautions be taken to prevent the heat from escaping. This can easily be effected by using a Dewar flask, or what is popularly known as a thermos flask, in which, as you know, the dissipation of the heat is reduced to a minimum by means of a surrounding vacuum.

Two such flasks were each filled with the same sample of wheat moistened until it contained $20^{\circ} 7$ per cent of water. To assist the process of heating, these flasks were kept in a warm incubator, under exactly the same conditions-save only that one was hermetically sealed while the other was merely plugged with cotton-wool, so as to allow of the access of air. Each flask was provided with a thermometer, the bulb of which was plunged in the wheat.

On March 7th--twenty-five days from the commencement of the experiment, the thermometer in the sealed flask still indicated only $28^{\circ} 1^{\circ} \mathrm{C}$. $\left(82.6^{\circ} \mathrm{F}\right.$.), just about the temperature of the incubator, while that in the ventilated flask had risen to $494^{\circ} \mathrm{C}$. $\left(121^{\circ} \mathrm{F}\right.$.). In other words, while the wheat in the ventilated flask had heated so as to cause a rise of temperature of no less than $38^{\circ} 4^{\circ} \mathrm{F}$., that in the sealed flask had not heated at all-or at any rate not to any extent worth noticing here. ${ }^{1}$ That the moistened grain, as placed in the

1 This experiment has since been repeated, the flasks being kept at room temperature, and similar results of a highly satisfactory character were obtained. 
thermos flasks, actually gave off large quantities of carbon dioxide when supplied with the necessary oxygen, was also proved by direct experiment, in which it was found that 50 grammes of the wheat gave off 121 milligrams of carbon dioxide in 24 hours. We shall return to this question later on.

Here, then, we have experimental proof that air-tight storage prevents heating even in grain containing a high percentage of moisture-very considerably higher, of course, than would be permissible in actual practice.

To the physiologist, of course, there is nothing surprising in these results, he could have predicted them all from purely a priori considerations. All the damage to stored grain which we have been considering is the result of vital processes connected with the metabolism of the organisms concerned, and such vital processes cannot go on without a supply of oxygen gas. It is merely another form of the time-honoured experiment of burning a candle in a closed vessel; as soon as the oxygen is exhausted the candle goes out. It is somewhat surprising, however, to find that the secret has been known so long by certain peoples who can have had little if any idea of the scientific principles upon which their practice is founded. I have already referred to the native Indian method of storing grain in air-tight pits. Much more remarkable is the practice of certain Natal farmers, who store their 
maize in large tanks of corrugated iron, in which they burn candles until the air is exhausted before closing them up, for the express purpose of preventing weevilling.

Although it may seem safe to conclude, from the evidence which I have already placed before you, that the immunity of the grain in air-tight receptacles from damage of various kinds is due to the gradual replacement of the oxygen in the air by carbonic acid gas, it was thought desirable to obtain more exact information as to what really takes place under these conditions. For this purpose a large number of analyses of the gases present in the sealed flasks, and a number of experiments on the effects of various gases and mixtures of gases upon the live insects have been made in my laboratory by Mr. Elkington. These experiments are not yet concluded, but I may place before you some of the preliminary results.

In the first place it is easy to demonstrate that ordinary clean commercial wheat, at ordinary temperatures, may give off considerable quantities of carbonic acid gas. For example-two lots, each weighing 300 grammes, of English wheat, having a natural moisture content of 15.9 per cent, were sealed up in two glass flasks for three months, the receptacles being nearly full. The experiment lasted from July 16th to October 17th, the flasks being kept at ordinary room temperature. At the close 
of the experiment it was found that in one flask $58^{\cdot 6}$ milligrams of $\mathrm{CO}_{2}$ had been formed, and in the other 56 milligrams; in the former the percentage of $\mathrm{CO}_{2}$ in the air in the flask was found to be $18 \cdot 13$, and in the latter $17 \cdot 82$.

The rate at which carbon dioxide is given off varies according to the amount of moisture present and according to the temperature, but in actual practice this could perhaps be regulated as desired. We have already had occasion to notice the large amount given off by wheat containing $20^{\circ} 7$ per cent of water at about $31^{\circ} \mathrm{C} .\left(88^{\circ} \mathrm{F}.\right)$.

If insects are present in the grain, the percentage of carbon dioxide rises more rapidly because the insects themselves produce very considerable quantities of this gas as a result of their own metabolism. Thus it was found that at room temperature $\left(63-66^{\circ}\right.$ F.) 100 rice weevils (Calandra oryzae) gave off 23.5 milligrams of carbon dioxide in 48 hours, while 100 grain weevils (Calandra granaria) gave off $19 \cdot 7$ milligrams.

Analyses have also been made of the gases present in the flasks in which weevils had been sealed up until they were killed. These experiments were made at $31^{\circ} \mathrm{C}$. $\left(88^{\circ} \mathrm{F}\right.$.), a temperature very favourable to the weevils under ordinary conditions. One hundred rice weevils were sealed up for 72 hours, with enough killed grain for them to feed upon, the killed grain giving off only a negligible quantity of 


\section{PHYSIOLOGY AND NATIONAL NEEDS}

$\mathrm{CO}_{2}$. At the end of that time they were all quite dead and the gas present in the tube was found to contain $17 \cdot 72$ per cent of $\mathrm{CO}_{2}$ and only 0.18 per cent of oxygen (in a duplicate experiment 17.97 per cent of $\mathrm{CO}_{2}$ and 0.12 per cent of oxygen). In other words, very nearly all the oxygen present at the commencement of the experiment had been consumed and replaced by carbon dioxide.

The question now arises-Is the death of the insects due to some poisonous action of the carbon dioxide or merely to the deprivation of oxygen? A number of experiments were made with a view to determining this point. In the first place it was found that weevils are soon killed by keeping them in an atmosphere of moist nitrogen, as pure as could be obtained. At the commencement of this experiment the atmosphere consisted of $98 \cdot 13$ per cent of nitrogen and 1.87 per cent of oxygen, no carbon dioxide being present. After being sealed up for 46 hours at $31^{\circ} \mathrm{C} .\left(88^{\circ} \mathrm{F}\right.$.) the weevils were all dead and only 0.89 per cent of carbon. dioxide had been produced. We may safely conclude in this case that it was the absence of oxygen which killed the weevils.

On the other hand we have abundant evidence that carbon dioxide, if present in sufficient quantity, does exercise a poisonous effect. In pure moist carbon dioxide rice weevils are rendered completely motionless in three minutes, and it is interesting to 
note that they can remain in this condition for a very long time and yet recover when again supplied with fresh air. Ten weevils were sealed up in practically pure carbon dioxide (99.8 per cent) at room temperature for four days ( 96 hours). They were then removed to ordinary air and incubated at $31^{\circ} \mathrm{C} .\left(88^{\circ} \mathrm{F}\right.$.), when 7 of them slowly revived and were still alive at the end of 48 hours.

At higher temperatures they cannot withstand the influence of the pure carbon dioxide for so long; nevertheless, even when kept all the time at $31^{\circ} \mathrm{C}$. $\left(88^{\circ} \mathrm{F}.\right)$, in one experiment all revived completely after 26 hours' exposure and in another 9 out of 10 revived after 42 hours.

If now, instead of using pure carbon dioxide, we use carbon dioxide with a moderate admixture of oxygen, we get a very different result, and one which $I$ think is of great interest and some novelty from the physiological point of view. Under these conditions the weevils again became completely motionless in a very few minutes, but they cannot remain so long under the influence of the gas without losing the power of revival. Thus, at $31^{\circ} \mathrm{C} .\left(88^{\circ} \mathrm{F}\right.$. $)$ in a mixture of 78.58 per cent $\mathrm{CO}_{2}$ and 21.41 per cent 0 , after only 21 hours there were no revivals. At the close of the experiment there was still 20.61 per cent of oxygen present, which again suggests that death was due to poisoning by carbon dioxide, certainly not to deprivation of oxygen. 
Much lower percentages of carbon dioxide, however, are sufficient to kill the weevils even in the presence of plenty of oxygen. For example, let me quote one of a series of experiments conducted at $31^{\circ}$ C. $\left(88^{\circ} \mathrm{F}\right.$.).' Ten rice weevils were sealed up in an artificial atmosphere containing $56^{\circ} 42$ per cent of nitrogen, 20.36 per cent of oxygen and 23.22 per cent of carbon dioxide. The weevils were all motionless in 43 hours. After 91 hours the flask was opened and the gas in it was found to consist of 56.30 per cent of nitrogen, 19.09 per cent of oxygen and $24^{\circ} 61$ per cent of carbon dioxide. Hardly any of the oxygen had been used up, but all the weevils were dead beyond the possibility of revival.

These experiments serve to show that pure carbon dioxide gas is actually less fatal than carbon dioxide with a moderate admixture of oxygen. I think the explanation is probably that in pure carbon dioxide all metabolism is completely suspended, the machinery of life is stopped short, so that the carbon dioxide cannot exercise its lethal effects, while, if there is enough oxygen present to maintain a certain amount of metabolism - though the insects remain apparently lifeless-the poisonous action of the carbon dioxide takes place.

I fear that I have wearied you too long with the dry details of experimental evidence, and will pass on at once to my concluding remarks. 
I hope we have demonstrated conclusively that the air-tight storage of grain is a perfectly rational method of treatment based upon a sound scientific foundation. It remains for the engineers and others to say how far it is practicable upon a large scale, but I may say that I have been assured on good authority that no serious difficulty would arise in the construction of air-tight stores or granaries.

If this is the case, I think that this system of storage ought to be very seriously considered by the proper authorities-whoever they may be.

If the grain were stored in this way in the country of origin for a few months before shipment, it would be completely sterilised as regards insect life, and with reasonable precautions on board ship it could not become infected during the voyage. Air-tight storage on the voyage might be a more difficult problem; its chief value would be to prevent the heating which takes place when the grain gets damp. If the grain were landed in this country in an insect-free condition there would be little risk of subsequent insect infection unless it were proposed to keep it for a long period, when air-tight storage might again be resorted to.

No doubt air-tight storage would involve a large expenditure of capital, but considering the immense amount of damage which might be prevented, this expenditure would in all probability be abundantly justified. Another advantage of air-tight storage 
in the country of origin would be the regulation of shipments thereby rendered possible-there would be no need for a rush to get the grain away as soon as possible after it was harvested.

If it should be decided to store large reserves of wheat in case of war, the air-tight method certainly seems to be indicated-both historically and scientifically-as the safest and probably the most economical in the long run-for there can be little doubt that if this method was properly carried out the wheat could be kept for many years with a minimum of inspection and attention.

I have, however, heard it suggested that the proper policy for this country is to encourage the farmers to grow more wheat, and thus render ourselves more or less independent of overseas supplies and large reserves. It may be so, but there is always the risk of failure of the harvest, as well as of shortage of labour, due to war or other causes, and a sufficient reserve at any rate to equalise supplies would seem to be only a reasonable precaution. That, however, is hardly our business. All we can claim is to have demonstrated the value of air-tight storage as a means of preventing most if not all of the damage to which stored grain is at present liable.

Experiments similar to ours ought, of course, to be carried out on a much larger scale than is possible in a university laboratory. I have no 
doubt of the result of such experiments if the proper conditions be observed, but I must once more insist upon the necessity of scientific accuracy in carrying them out.

In the meantime it is satisfactory to be able to state that in Australia, where the weevil problem is now very serious, some of the investigators are working along our lines and the value of air-tight storage is beginning to be appreciated. We learn from the Journal of the Department of Agriculture of Victoria that a conference on the subject of the weevil pest was held in Melbourne in October last, under the presidency of Professor Orme Masson, F.R.S., Deputy Chairman of the Commonwealth Advisory Council of Science and Industry. Experiments in sealing up weevily wheat in jars had been made by Mr. Spafford, evidently very similar to ours. Indeed, the Chairman called attention to the fact that the results as to the asphyxiation of weevils were in complete accord with those obtained by myself in England.

As regards treatment of the wheat on a large scale very important results were obtained with a stack of 8500 bags of very weevily wheat, which was covered with a material called malthoid to make it as air-tight as possible, after which carbon dioxide gas was pumped in. The result was regarded as highly satisfactory, but of course it would have 
140 PHYSIOLOGY AND NATIONAL NEEDS

been more so had a properly constructed air-tight silo been available, in which the weevils could undoubtedly have been killed in the natural course of events, without the trouble and expense of preparing and pumping in artificial gas. 


\section{PHYSICAL TRAINING AND THE OPEN-AIR LIFE}

BY

M. S. PEMBREY, M.A., M.D.

LEOTURER IN PHYSIOLOGY AT GUY'S HOSPITAL 



\section{PHYSICAL TRAINING AND THE OPEN-AIR LIFE}

MODERN civilisation has been maintained by a constant struggle against physiological principles. The results have been wonderful, but it cannot be said that they have produced satisfaction and contentment among mankind. There are widespread unrest and discontent, and the question arises whether guidance might not be obtained from physiology. May it not be wiser to accept the fundamental principles of life, which are the same for all classes, give up the endless struggle and adjust the conventions of civilisation to those principles? A full discussion would involve the physiology of everyday life and would raise questions upon which men feel strongly, but in this lecture only the physical training of the body and its relation to an openair life will be considered.

Few would doubt that in the beginning man obtained his physical training in a similar manner to that which obtains among animals, and was obliged to spend a large part of his life in the open air. In suitable surroundings the body attained 


\section{PHYSIOLOGY AND NATIONAL NEEDS}

physical fitness; the training was part of life itself. The advances of civilisation, especially in locomotion and industry, have prevented in countless cases the development of physical fitness, or have brought about degeneration. This has been recognised, and attempts to counteract it are found in legislation dealing with industrial employment and schemes of infant welfare, boy-scouts, cadet corps, compulsory physical training in schools and conscription for military service.

Atrophy from disuse is a fundamental principle of life, and any one, who has eyes to see, can find the proofs. Let him contrast the feeble and clumsy flutter of a domesticated duck with the swift, strong and controlled flight of the wild duck; compare the pot-bellied hutch-rabbit with rabbits of the same breed turned loose in the woods, the wild boar with the domestic pig, or the mountain sheep with the sheep which are confined to their pens. It matters not if objection be raised on the grounds of selective breeding. The young of such breeds show much of the primitive capacity of their ancestors and this capacity will result in physical fitness, if the opportunity and stimulus are supplied.

Under natural conditions the development of physical fitness requires no special safeguards, the capacity is within the germs at the time of conception and it is as easy (if not easier) to understand a perfect and symmetrical growth as an 
abnormal one. The build of the body depends chiefly upon the characteristics transmitted by the ancestors and has been determined in great part even before birth. At the very beginning of existence animals have a potential fitness for some special mode of life; some will become swift runners, others divers and other flyers. In them no system of physical training has been handed down by tradition; the opportunity for exercise is all that they require, and the result is a physical fitness which excites our admiration. Here at this early stage physiology comes into conflict with those keen reformers and educators, who will not see the problem as a whole. One-sided schemes may be excellent in their design, but they will not produce physical fitness. Ante-natal treatment, infant welfare, medical and dental inspection of school children, physical drill in schools and the like are not based upon broad physiological principles. Only the sick need the physician. Physical training is a question of physiology, not of medicine or surgery ; its aim is the healthy performance of all the functions of the body and the development of a resistance to the noxious factors of life.

It will be well now to consider the natural processes of physical training from birth onwards. The healthy infant needs only the instinctive care that wild animals devote to their young. It does not require to be taught to live by an educated mother 
or nurse. It suckles and takes its food according to its needs, not, as the modern nurse thinks it should, according to the clock. It breathes through its nose because there is less effort required to keep the mouth closed than open, and when it suckles it must breathe through the nose. As the infant grows it learns to control the muscles of its limbs, it crawls and walks, and is not taught, notwithstanding the claims advanced by many a fond mother. The capacity is within itself in the same measure as in the young of other animals. Still later the child begins to play and thus trains not only its muscles and its senses, but all parts of the body. By exposure to the open air and changes of temperature it learns unconsciously to regulate its production of heat and acquires control over the vascularity of its skin. Its fondness for playing in the dirt and total disregard of every dogma about germs will increase gradually its resistance and raise its immunity.

When boyhood is reached the games and sports become more complicated and strenuous, involve the training of all the senses and the co-ordinated working of all the systems of the body. Teamwork produces discipline, healthy competition and endurance; at the same time games give ample scope for individuality. There is the great advantage that the muscular work is done with pleasure and, in the vast majority of cases, with no ulterior 
motive. Games and sport involve an open-air life with exposure to all the influences of climate; in summer the intense sunlight produces obvious chemical effects in the body, as shown by the sunburnt skin; in winter the cold increases muscular activity and nutrition; every change of weather demands an adaptation of the body. There is little doubt that as a nation we owe much to our variable and uncertain climate and to our devotion to outdoor games and our primitive open fires.

From birth to boyhood there is a progressive training for physical fitness, and all that is needed is freedom in the open air; for the healthy child, as is the case with other young animals, possesses an instinct to play, will evolve its own games and introduce and enforce the ideas of leadership, discipline and efficiency. The games, moreover, are adjusted to the seasons and possess sufficient variety to prevent monotony or one-sided development.

All the foregoing remarks are but the statement of common knowledge and contain nothing new. The athletic youth of the country have learnt by experience the truth, but that unfortunately has not guided those who legislate and govern. Sixty years ago Herbert Spencer in his essays "On Education" protested against the neglect of the teachings of physiology. The need of reform is as great, if not greater, now, for the advances in civilisation have imposed a heavier task upon man- 


\section{8}

\section{PHYSIOLOGY AND NATIONAL NEEDS}

kind. The Inter-departmental Committee on the Model Course of Physical Exercises reported to the Board of Education in favour of a system of drill which has no sound physiological basis and is deadly dull. As in the services, so in schools, drill is used as a punishment. Many schools have no playground, but it is proposed to supply them with a gymnasium, for it is stated that " in a climate such as ours exercises in the playground must necessarily be suspended for weeks together." Such is not the way to increase the physical fitness of children and their capacity to resist the vagaries of our climate : far better results would be obtained at less cost by providing ample playgrounds for games organised by the children and played during school hours. Drill indoors increases the risk of infection and lowers the resistance to disease; the fatigue produced by drill is out of proportion to the exercise involved; there is an absence of pleasure, freedom and scope for individuality.

Physical training is most necessary during the years of growth, but it is also essential for the adult, if he is to live a full and healthy life. Manual labour may in certain instances supply in itself all the conditions necessary for the maintenance of physical fitness. Such is the case in the oldest of the industries, agriculture. The farm labourer has most varied work in the open air at all seasons of the year and is not subjected to continuous hard 
work; the pace is not determined by machinery, but by the weather and the condition of the soil and crops. It is one of the most healthy occupations and, although the low wages have not attracted the best types of manhood, a good standard of physique has been maintained, and unrest and strikes are not generally associated with work on the land. Coal miners belong to a modern industry; they are as a class very healthy, brave and efficient men; they do not work in the open air, and have strenuous and monotonous labour in constrained positions, but they have compensated for these drawbacks by insisting on shorter hours of labour and higher pay ; their strikes have been the expression of their physiological needs, a high standard of food and recreation in games and sport in the open air.

The healthy man is not injured by hard muscular work, when he himself sets the pace and is guided by his own sense of fatigue. The evil arises when a machine, which has no soul, sets the pace; then the workers can escape degeneration only by insisting on shorter hours. In fact there appear to be legitimate grounds for discontent in much factory work, for the conditions pay little regard to physiological needs. A monotonous piece of mechanical work, such as feeding a machine day in and day out throughout the year, is bad; it leads to work, which may be done reflexly and with little effort, but it is so one-sided that pleasure is absent, other 
parts of the body are not exercised adequately, and the only interest is to get the work over and earn the money. A change of work is as good as play, even if it may involve a greater muscular effort. Variety causes a new adjustment of bodily activity and tends towards physical fitness. Even sports and games become labour if they are followed continually as occupations; the sportsman will pay large sums for shooting and fishing rights, but the gamekeeper and the fisherman expect to be paid for their labour. Work in the open air has the advantage that the climate, at least in this country, will introduce some variety from day to day.

Muscular work is a necessary condition of physical fitness; those who are not forced to work for their living find salvation in games and sport. There is therefore no hardship if the manual labour is performed under the best conditions. The determination of this optimum is a question for physiological investigations, for machinery and factory life have introduced disturbing influences.

If further evidence were needed of the beneficial effects of muscular exercise in the open air, it is only necessary to consider the sick rate of soldiers in barracks compared with that of the same men during manœuvres; the open-air treatment of diseases, especially phthisis; the success of outdoor schools for children; the value of convalescent hospitals in the country and the great progress in 
the treatment of disease by remedial exercises in the open air. There are involved here far more factors than pure air ; the influences are exposure to changes of temperature, moisture and wind, which produce physiological responses in the organism. The resistance is raised, and only thus can the ravages of epidemics be avoided. A mild attack of disease will lead to immunity. It is impossible, even if it were desirable, to abolish disease and death, but it is possible to increase greatly the resistance of a nation to the diseases which are common in the country.

Thus far the subject of physical training and the open-air life has been considered from a general standpoint, and the arguments brought forward are such that the layman can estimate their worth. It will be convenient now to show the agreement of physiological knowledge with the experience of athletes, sportsmen and labourers. Such a comparison will be obtained most readily by a consideration of the different systems of the body in relation to physical training and life in the open air.

The Circulation of the Blood.-The heart, the pump which drives the blood round the body, is one of the most important factors concerned in physical training. It pumps the blood through the lungs, and in this respect is an essential component of a "good wind," for it is useless to ventilate the lungs if the blood does not circulate rapidly enough 
for the efficient removal of carbon dioxide and the necessary absorption of oxygen. Athletes and the trainers of racehorses and greyhounds have learnt from experience the correct way to train the heart. That organ is a muscle and must be trained by progressive work. Its rate of contraction varies in different healthy men; it may be fifty or seventy beats per minute during rest. There is no uniformity in rate, but in all men there is a response to exercise, an increase, it may be, to one hundred and sixty beats per minute. The man with the slow pulse at rest has a greater range before he reaches the speed-limit of the heart during severe muscular work. It has been found that many of the best athletes have a very slow pulse during rest, and the general effect of progressive muscular exercise is to produce a slow beat of the heart during rest and a more rapid return to this rate after strenuous exercise. A weak heart is not made stronger by the avoidance of muscular work; it should be exercised by slowly increasing the amount of work.

Physiological knowledge agrees with sound experience, for the latter is in reality the result of numerous physiological experiments; but they are equally in conflict with the erroneous ideas of some authors of systems of physical training, who by drill movements aim at expanding or opening out the chest in order, as they say, to give the heart 
more room in which to work. A little knowledge of anatomy and physiology has led these authors astray; they do not recognise that a vacuum cannot be produced in the chest and the ribs are moulded to the shape of the underlying organs.

The circulation of the blood is not only necessary for the nutrition and purification of the body, but is also a means for regulating the temperature of the body by the exposure of more or less blood in the numerous small blood-vessels of the skin. Exercise and life in the open air train and increase the capacity for this adjustment.

The Respiratory System interests every man, for he regards the first breath at birth as a proof of life and the last breath as evidence of death. It is only natural, therefore, that it should have received the special attention of authors of systems of physical culture. They argue that special breathing exercises are necessary to make the lungs more efficient in their work of absorbing the life-giving oxygen and discharging the poisonous gas, carbon dioxide. Such breathing exercises, notwithstanding the fact that they have been approved by the Board of Education, are absurd in theory and useless or even dangerous in practice. The body is a living organism, not a blast furnace ; it does not take up more oxygen than it requires, however much the lungs are ventilated, and if too much carbon dioxide be removed the subject 
becomes giddy and stops breathing. Another result of this exercise, performed in a school-room, is that the spray of the breath containing any infectious germs, 'which may be present in the throats of some members of the class, is spread broadcast and is inspired by others. It is no wonder that compulsory education and breathing exercises have coincided with numerous epidemics among school children.

Healthy children do not require teaching how to breathe; they are trained unconsciously by their running in the open air. Athletes and the trainers of racehorses have learnt by experience the correct way to train the lungs. By progressive muscular exercise the respiratory system is stimulated in the natural manner ; the activity of the muscles during running produces a great output of carbon dioxide and uses up much oxygen, the nervous system responds to the changes in the composition of the blood, and the respiratory muscles contract more frequently and forcibly. A further advantage is that the heart is stimulated and trained at the same time.

Gymnastic exercises have been devised for the purpose of expanding the chest. The result may be seen in soldiers, who tend to fix their chests in a partly distended condition. The increased girth of the chest produced in this way is often only apparent, and is due in some cases to a special 
development of the muscles of the chest and in others to a forcible displacement of the stomach upwards to the chest. A big chest is no proof of a "good wind," although it is true that healthy men who have led an active life in the open air possess well-developed chests. "Wind" depends upon the capacity of the heart and lungs to accommodate themselves to the demands made upon them by muscular work.

There is another objection to breathing exercises. The authors of systems do not agree in their teachings ; some urge thoracic, others abdominal breathing. This lack of agreement would be expected, for the natural types of breathing vary not only in different individuals, but even in the same individuals according to the conditions involved during rest and various kinds of work. In exercises demanding especially the use of the arms the upper portion of the thorax must give a fixed point of purchase for the muscles, if efficiency is to be obtained. Women with little muscular development show very definite respiratory movements in the upper part of the thorax; this is due, no doubt, partly to the constriction of the abdomen by corsets, but in part only, for directly they perform much hard work with their arms, abdominal breathing is increased and thoracic diminished. Muscular exercise or work abolishes tight lacing in women, and the converse is equally true. 
The Muscular System cannot be trained properly by gymnastic exercises devised on anatomical grounds to produce the development of each muscle. Agility and capacity to perform movements smartly cannot be obtained by developing big muscles by special bends or exercises with dumb-bells or heavy weights; the body may become "muscle-bound." If a boy wishes to become a runner he must practise running; if he will become a good oarsman he must row ; if he must perform any given work efficiently he must learn by doing it. Practice alone makes perfect, provided always that there is within the man the latent but special capacity necessary for excellence. The diversity and graduation of the muscular exercise involved in the numerous forms of outdoor sports render them suitable for all men, young and old, strong and weak.

The Nervous System is trained by games and sports in a far more efficient manner than by drills and gymnastic exercises. The muscles in response to nervous impulses contract in ordered groupings for a definite purpose, the contraction of some being accompanied by the relaxation of others. To facilitate the muscular work the nervous system co-ordinates the respiration, the heart and the glands of the body. At the same time that there is an outflow of nervous impulses there is also an inflow from the various sense organs; the eye, the 
ear, the muscular sense, the senses of temperature, pressure, touch and equilibrium are trained by the work. The relaxation afforded by games and sport, or even by a change of work, is the natural safeguard against the nervous breakdown which is too common among civilised men and women, who become slaves to their work and cultivate their ambition until it becomes an obsession and a vice. The best method of inducing healthy sleep and restoration is muscular fatigue of moderate degree ; muscular exercise or work cannot be performed without nervous activity, but severe mental work is often unaccompanied by muscular activity sufficient to produce those complex chemical changes which accompany healthy fatigue.

The Digestive System in the healthy man must respond to muscular activity, for the work performed is at the expense of the energy supplied by the food. Experience has always shown that men and horses feed best when they are well worked, and work best when they are well fed. Exposure to cold has a similar stimulating effect, for muscular tone and activity are increased in order to produce more heat for the maintenance of the temperature of the body. The man who takes sufficient exercise daily runs no risk of becoming corpulent or overfed when he eats as much as he desires, and a sturdy growth of children is not to be obtained by the intelligent selection of the quality or quantity 
of their diet, but by the natural process of muscular activity in the open air, the appetite with its likes and dislikes acting as the guide in questions of food.

The Cutaneous System plays an important part during muscular work, for the secretion of sweat and the flushing of the skin with blood prevent any abnormal rise in the temperature of the body. The skin is moreover the largest sensory area of the body, and exercise in the open air exposes it to heat and cold. In such a manner accommodation to changes of temperature is developed. This is called the "hardening process," and possesses a sound basis. Some of the beneficial effects of sunlight are known, but much remains to be discovered.

There is no time for a more detailed consideration of the effects of physical training and the open-air life. There are, however, a few points which must be mentioned. The living body is constantly compared with a machine, and the effects of work are considered from that point of view. It is forgotten that the body is more wonderfully and perfectly made than any machine. It possesses the power of self-adjustment and repair; with use it grows and becomes stronger and at the same time more economical in its working. It cleanses itself and is self-guided to supply the energy requisite for its work and the rest necessary for its restoration. It has a range of adaptation to different kinds of 
work and a duration of life far greater than any machine; long before it has reached its maximum of efficiency it can reproduce its kind.

In conclusion it may be stated without any doubt that the true method of physical training is muscular exercise in the form of games, sport or work in the open air, for this is the one based upon biological principles. On these lines it is possible to improve greatly the health of the nation. It is cheaper in the long run to raise healthy than unhealthy stock, but it is not safe to argue that the latter should be "scrapped," for civilisation is so complex in its demands that a man possessing a very poor physique but a special type of mental capacity may be more valuable to the State than many healthy men. 



\section{INDEX}

Accessory food substances, see Vitamines

Agricultural life, 148

Air-tight storage of grain, 120 et seq.

Alcohol, 7

Antiscorbutics, 60

Atrophy from disuse, 144

Bacteria in grain, 117

Beer and scurvy, 66

Beri-beri, 11, 31, 39

Blood pressure, 90

Bread, 12

Bread, white and brown, 45

Breathing exercises, fallacy of, 153

Butter, 13

Calories, 10, 20

Carbonic acid, action of on weevils, 123 et seq.

Cereal reserves, conservation of, 105 et seq.

Chlorine, 4, 83

Circulation, side-tracking of blood in, 91

Circulation and natural life, 151

Cocoa butter, 17

Cod-liver oil, 42

Colloidal state, 93, 100

Cooking and scurvy, 61

Cutaneous system, Nature's method of regulating, 158

Deficiency diseases, 16

Dieting, principles of, 10, 19-24

Digestive system and the open air, 157

Disease and physiology, 77 et seq.

Drowning of lung, 84

Endowment of research, 6

Exercise, 152
Fat-soluble A, 38

Fat supply, 13

Fatty acids, 13-15

Food (War) Committee of Royal Society, 8

Food control, 8

Food-values, 10

Games, 146 et seq.

Gassing, 82

German organisation, 18

Glycerine, 13, 15

Goitre, 96

Grain, sources of damage to, 106 et seq.

Grain Pests (War) Committee, 109

Guanidin and tetany, 98

Guinea pigs and scurvy, 56

Gum in transfusion, 93

Gymnastic exercises, 156

"Heating" of stored cereals, 110, 118,128

"Hermetically sealed" tins, 126

House-building analogy, 36

Human scurvy, 62

Hygiene an outcome of physiology, 3

Interallied Food Commission, 9

Knowledge, pursuit of, 101

Lanoline, 17

Lime and lemon juice, 67

Margarine, 16

Medical Research Committee, 6, 89

Milk and milk products in relation to scurvy, 69

Milk legislation needed, 17 


\section{PHYSIOLOGY AND NATIONAL NEEDS}

Milling machinery, 31

Minerș, life of, 149

Monkeys and other animals, scurvy in, 63

Monotony, evils of, 149

Mothers, diet of, 49

Moulds in damaged grain, 117

Nervous system, natural training of, 156

Open-air life, 143 et seq.

Open-air treatment, 150

Oxygen deprivation in grain storage, 134

Oxygen in gassing, 85

Parathyroids, 97

Pellagra, 44

Phosgene, 83

Physical drill, 145, 148

Physical training, 143 et seq.

Physiology, its usefulness in general, 3-5

Physiology and disease, 77 et seq.

Pigeons and neuritis, 40

Prisons in Japan, 32

Purified foods, 34
Respiration, natural, 153

"Respiration" of grains, 118

Rice as food, 11, 30

Rickets, 41, 48, 95

Science and food, 27

Science and war, 4

Scurvy, 43, 53 et seq.

Scurvy, experimental, 56

Shock, 88

Silos, air-tight, 140

Sport and games, benefits of, 159

Teeth and deficient diet, 42

Tetany, 95

Thyroid, 96

Transfusion, 93

Vegetable fats, 16

Vitamines, 11, 16, 27 et seq.

Vitamines, distribution of, 39,58 , 59

War and science, 4

War bread, 12

Water-soluble B, 38

Weevils, 110 et seq.

Wound shock, 88

THE END

Printed in Great Britain by R. \& R. CLARK, LIMITED, Edinburgh. 


\section{FROM CONSTABLE'S LIST}

ANIMAL LIFE AND HUMAN PROGRESS. Edited by Prof. Arthor Dendy, D.Sc., F.R.S. 10s. 6d. net.

"This volume is the outcome of a series of Lectures organised by Prof. Dendy at King's College, London. . . . The College and the Editor are to be congratulated on their courage and public spirit, and on having made the subject-matter accessible to all through the medium of this volume."-Nature.

\section{OUTLINES OF EVOLUTIONARY BIOLOGY. By ARthor Dendy, D.Sc., F.R.S. Fully Illustrated. Second Edition, enlarged. Fourth Impression. 15s, net.}

\section{THE PROFESSION OF CHEMISTRY. By RICHARD B.}

PILCHER, Registrar and Secretary of the Institute of Chemistry of Great Britain and Ireland. Crown 8vo. 6s. 6d. net.

In consequence of his position Mr. Pilcher has been able to accumulate information on both the educational training required and the prospects and conditions of practice of every kind of chemist. $\mathrm{He}$ is in an unrivalled position to advise and direct those who would enter a profession which is expanding steadily by reason of its essential importance to our industries.

THE SUBCONSCIOUS. By Joseph Jastrow. A Study in Descriptive Psychology. Extra Crown 8vo. 10s. net.

THE MECHANISM OF MENDELIAN HEREDITY. By Morgan, Sturtevant, Muller, and Bridges. Demy 8vo. Illustrated. $12 \mathrm{~s} .6 \mathrm{~d}$. net.

"... deserves the most careful consideration from students of heredity . . a book which treats of one of the most important and novel lines of biological research."-Journal of Zoological Research.

\section{ECONOMIC ZOOLOGY AND ENTOMOLOGY. By}

Vernon L. Kellogg and G. W. Doane. Crown 8vo. 6s.6d.net.

In this elementary text-book the authors have produced an introduction both to general zoology as well as to economic zoology.

A TEXT-BOOK OF GENERAL EMBRYOLOGY. By William E. Kellicott. 10s. 6d. net.

". . a most admirable and thoroughly justifiable addition to the books on embryology in the English language ... does distinct credit to American scientific scholarship."-British Medical Journal.

\section{OUTLINES OF CHORDATE DEVELOPMENT. By}

William E. KeLlicott. 10s. 6d. net.

"Lucid, succinct and attractive . . most valuable to students of the fascinating subject with which it deals."-Lancet. 


\section{FROM CONSTABLE'S LIST-Continued.}

HANDBOOK OF THE TECHNIQUE OF THE TEAT AND CAPILLARY GLASS TUBE. By Sir Almroth E. WRIGHT, M.D., F.R.S. 10s. 6d. net.

ON PHARMACO-THERAPY AND PREVENTIVE INOCULATION. Applied to Pneumonia in the African Native. By Sir Almroth E. Wright, M.D., F.R.S. 4s.6d. net.

LESSONS IN ELEMENTARY TROPICAL HYGIENE. By Henry Strachan, C.M.G. 1s. net. For the Use of Pupils in Tropical Schools.

POST-MORTEMS AND MORBID ANATOMY. By Theodore Shennan, M.D., F.R.C.S.E. Royal 8vo. Photographs and Coloured Plates. 18s. net.

".. the most complete and well-balanced text-book in English dealing with practical pathology."-Nature.

\section{PUBLICATIONS OF THE UNIVERSITY PRESS, LIVERPOOL}

PRACTICAL STUDY OF MALARIA AND OTHER BLOOD PARASITES. By J. E. Stephens, M.D., D.P.H., and S. R. Christophers, M.B., I.M.S. Third Edition. 12s. 6 d. net.

FASCICULI MALAYENSES. Anthropological and Zoological results of an Expedition to Perak and the Siamese Malay States, 1901-2, undertaken by N. AnNandale and H. C. Robinsox. In eight sections, 4to. Zoology, Part I., 30s. net; Part II., 20s. net (Appendix to Part II., 1s. net); Part III., 30s. net ; Part IV., 1s. net. Anthropology, Part I., 15s. net; Part II., 10s. net. Supplement, containing map and itinerary, 5s. net.

A NEW DISCOVERY OF THE OLD ART OF TEACHING SCHOOL. By Charles Hoole. Reproduced from a copy of the edition of 1660 . Edited with introduction and full bibliographical notes by E. T. Campagnac. Crown 8 vo. 7s. 6d. net. (1913.)

LUDUS LITERARIUS (or the Grammar Schoole). By J. BRINSLEY. Edited with introduction and full bibliographical notes by E. T. CAMPagnaC. Reproduced from a copy of the edition of 1627 . Crown 8 vo. 10s. 6d. net. (1917.) 




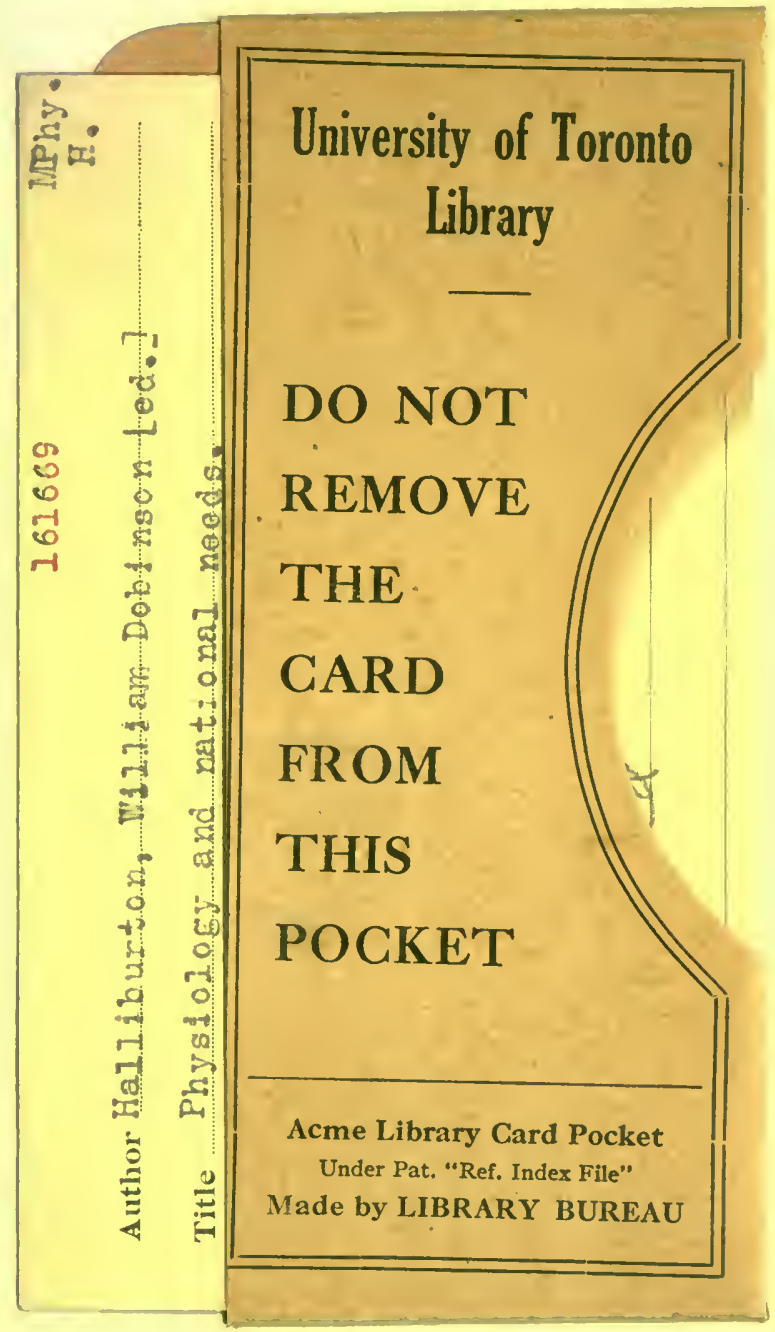




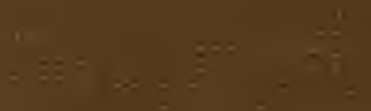

i. 58 :

$\therefore$

$\because+\cdots=0 ; \cdot 00$

$20,8=0$

$\operatorname{cosec}$

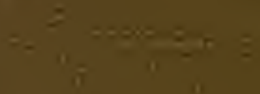

$+38=80$

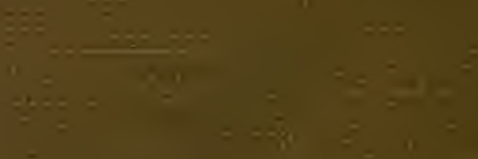

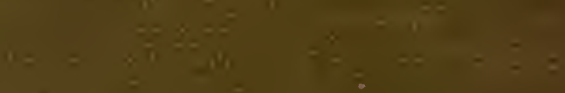

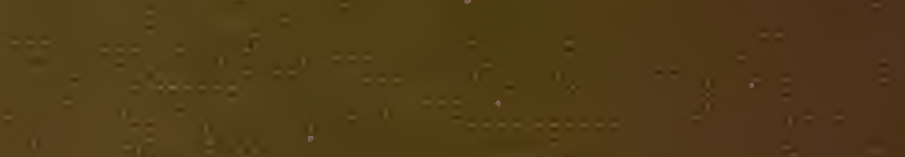

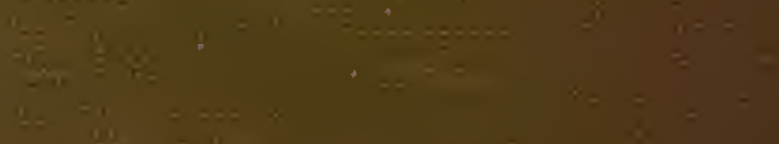

1. $\quad 2=000=18$

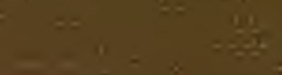

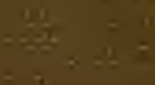

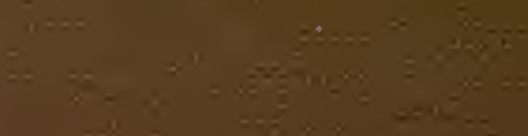

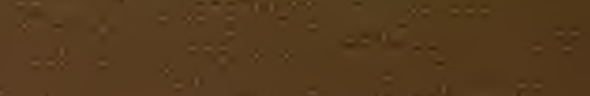

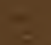

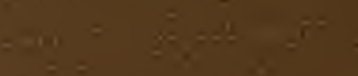

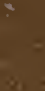

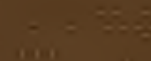

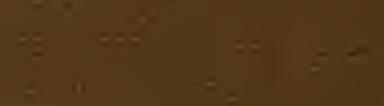

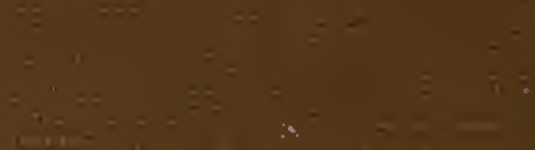

